Volume (4) No. (2) 2021

الإسهام النسبـي للحساسية الانفعالية والقلق والاكتئاب في التنبؤ بجودة الحياة لدى طلاب الجامعة

أ.د. علي محمود علي شعيب 
الإسهام النسبي للحساسية الانفعالية والقلق والاكتئاب في التبؤ بجودة الحياةلدئ طلاب الجامعة

$$
\text { أ.د. علي محمود علي شعيب }
$$

Alishoeib2004@yahoo.com أستاذ الصحة النفسية، كلية التربية، جامعة المنوفية، مصر،

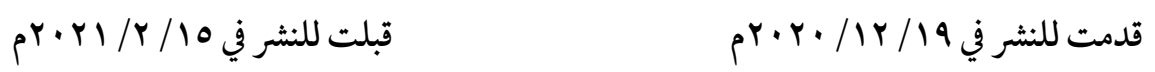

ملخص: هدفت الدراسة المى التعرف علن العلاقة بين جودة الحياة وكل من القلق العام والحساسية الانفعالية والاكتئاب لدىن طلاب الجامعة. كما هدفت إلى التعرف علن الإسهام النسبي للمتغيرات المستقلة القلق العام، الحساسية الانفعالية، الاكتئاب في التنبؤ بجودة الحياة لدئ طلاب الجامعة. وهدفت الدراسة المى التعرف علن الفروق في جودة الحياة بحسب مستويات القلق والاكتئاب والحساسية الانفعالية. كما هدفت المى التعرف علنى الفروق بين الجنسين في المتغيرات: جودة الحياة، القلق العام، الاكتئاب، الحساسية الانفعالية. كما تعرفت الدراسة على درجة شيوع هذه المتغيرات بين طلاب الجامعة. استخدمت الدراسة عينة قوامها سا ـ ـ من الذكور والاناث الدارسين بكلية التربية، كما قامت بتعريب أدوات الدراسة القلق العام، والاكتئاب، والحساسية الانفعالية وجودة الحياة والتأكدمن ثباتها وصدقها. ومن أهم النتائج التي توصلت اليها ان أكثر العوامل المنبئة بجودة الحياة: القلق العام بنسبة

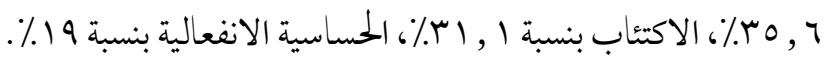
الكلمات المفتاحية: القلق العام، الاكتئاب، الحساسية الانفعالية، جودة الحياة 


\title{
The relative contribution of emotional sensitivity, anxiety and depression in forecasting quality of life of university students
}

\author{
Prof. Dr. Ali Mahmud Shoeib \\ Professor of Mental Psychology, College of Education, Menoufia University, Egypt, \\ Alishoeib2004@yahoo.com
}

Presented in 19th December 2020

Accepted in 15th February 2021

\begin{abstract}
The study aimed at investigating the relationship between quality of life and both general anxiety, emotional sensitivity and depression among university students. It also aimed at investigating the relative contribution of emotional sensitivity, general anxiety and depression in forecasting quality of life of university students. The study aimed also at identifying the differences in the quality of life according to levels of general anxiety, depression and emotional sensitivity. It also aimed at identifying the differences between males and females in the variables: quality of life, general anxiety, depression and emotional sensitivity. The study also identified the degree of prevalence of these variables among university students. The study used a sample of (1013) males and females studying at the College of Education. It also modified into Arabic the study tools: general anxiety, depression, emotional sensitivity and quality of life and ensured its consistency and validity. The results showed that the most predictive factors for quality of life are: general anxiety by $35.6 \%$, depression by $31.1 \%$ and emotional sensitivity by $19 \%$.
\end{abstract}

Key words: general anxiety, depression, emotional sensitivity, quality of life 
يعيش الإنسان كمخلوق اجتماعي في بيئة تتضمن عناصر إنسانية ترغب في التفاعل والارتباط

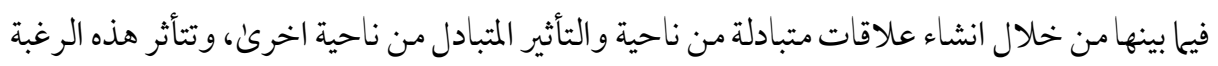
الاجتماعية باحتمالية الرفض rejection للفرد من الاخرين، إلا أن البعض ممن يعانون الحساسية الانفعالية قد يستجيبون بحالة من سوء التوافق، لذا فان الحساسية الانفعالية تشير المن رغبة الفرد القوية في التفاعل مع الاخرين إلا أنه يستشعر التجاهل منهم (Barbieri, 2020, p. 1).

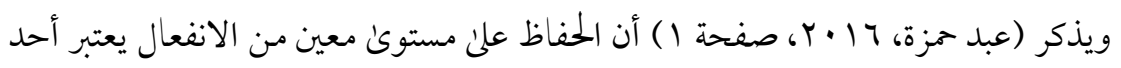
متطلبات الحياة المتكيفة فاذا اختلت عن وضعها الطبيعي بالزيادة او النقصان كانت سبا في الاضطراب ونشأة المرض النفسي. ولعل هذا يشير للأثثر السيء للانفعالات علن المستوئ الشخصي والاجتماعي مما يزيد من ردود الأفعال السلبية والاحساس بالإحباط و الوحدة النفسية. وعلى مدار الأربعين عاما الأخيرة، حاول الباحثون فهم العلاقة بين الاضطر ابات الانفعالية

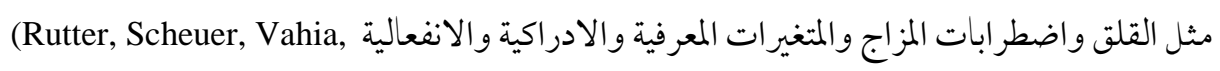
(Kraines, Kelberer, \& Wells, 2018, p. 31) وتشير إن .Forester, \& Germine, 2019, p. 1) الحساسية الانفعالية تعتبر أحد المسببات المؤكدة للاضطر ابات الانفعالية كالقلق والاكتئاب.

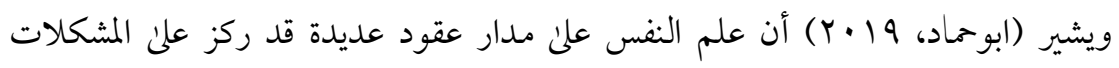
و الاضطر ابات النفسية دراسة وتشخيصا وعلاجا في حين أهمل الجموانب الإيجابية في شخصية الانسان الما حد كبير، إلا إنه مع بداية القرن العشرين ومطلع الالفية الثالثة، ظهر الاهتحام بجواب إيجابية في

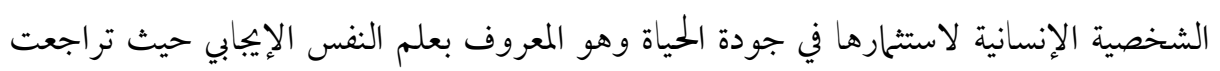
مفاهيم سلبية كالمرض والعو امل المسببة للاضطر ابات النفسية وبدأ استبداها بالرضا عن الحياة واللياقة النفسية psychological well-being والرضا عن الحياة والتفاؤل وتقدير الذات الإيجابي. فالمكتئب قد ولد يشعر بجودة الحياة في السعادة الا ان المتشائم قد يشعر بها في التفاؤل. ويذكر أيضا ان متغير جودة الحياة 
النفسية بات من المتغيرات التي تشغل بال الباحثين في العقود الأخيرة لماله من أهمية في الارتقاء بالصحة النفسية الإيجابية للفرد.

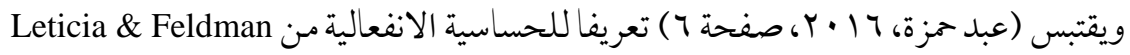

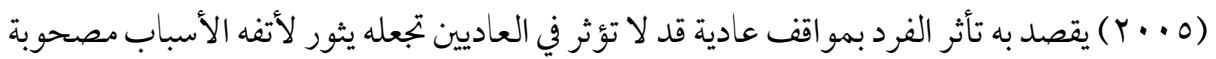
بردود أفعال تبدو عنيفة ومتهورة لا يمكنه التحكم فيها تناظر ردود الأفعال الانفعالية الطفلية. ويذكر أيضا ان الحساسية الانفعالية يمكن اعتبارها بجموعة من السمات الشخصية التي اولاها الباحثون اهتمامـا متأخر ارغم وجودها وشيوعها بين الافراد. وتذكر (ابو منصور، ||lY) بجموعة من السمات الخاصة بالشخصية الحساسة انفعاليا مثل الاستقلالية، الحذر، الدفاع عن النفس، الحساسية للنقد، الادراك و الوعي والإخلاص. كما أن هناك مجموعة من الأفعال المسيطرة في الشخصية الحساسة الانفعالية مثل صعوبة انشاء العلاقات بمبدأ الامن والأمـان من الاخرين، نجاحهم في الكشف عن البواعث الخفية لدئ الاخرين من خلال الحذر الشديد

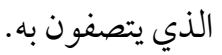

ويوضح (Perdighe, et al., 2015, p. 350) أن حساسية القلق عامة والحساسية الانفعالية خاصة قد ظهرتا في ميدان علم النفس الاكلينيكي علن يد Reiss and McNally عام 1910 ــ وتمت

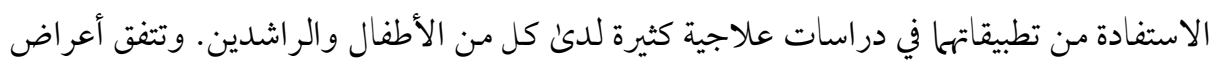
حساسية القلق anxiety sensitivity مع عدد من الاعر اض المصاحبة للقلق مثل عدم انتظام ضربات القلب والاحساس بالدوخة وضيق التنفس بها يجعل لهذه الاعر اض نتائج كارثية من حيث فقد السيطرة علن الانفعالات او الاغاء او اصدار تقييات سلبية تتيح له الدخول في نوبة فعلية حقيقة للقلق. وتشير

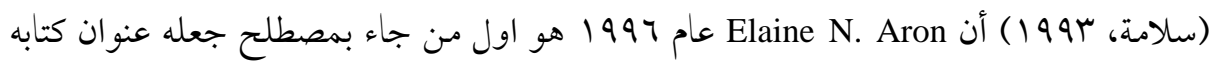

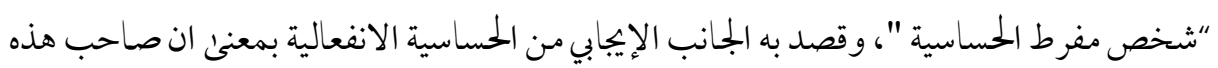
الشخصية يفكر مليا قبل ان يتصرف بالإضافة الما تعاطفه مع الاخرين. 
إن الحساسية الانفعالية لها وجهان أحدهما ايجابي يتمثل في انشاء علاقات التواد والتعاطف،

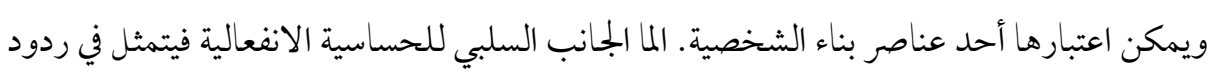

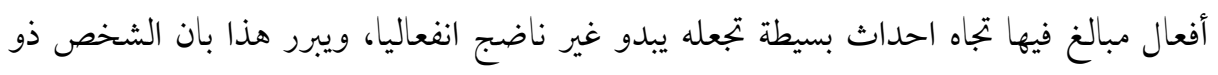

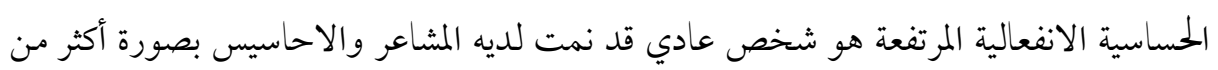

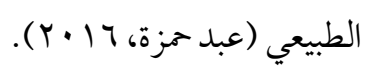

كما أن الحساسية الانفعالية تمثل نموذجا دفاعيا ينشط في ضوء التفاعل الاجتماعي بهدف إظهار

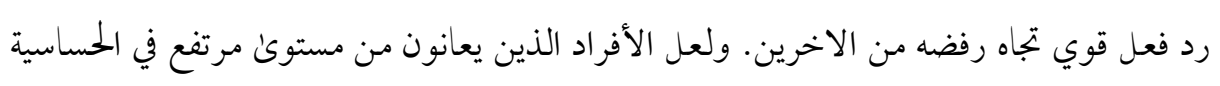

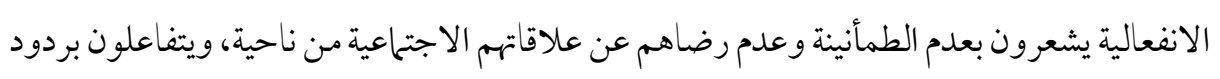

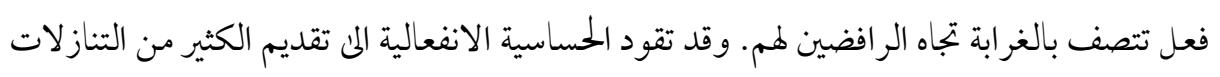

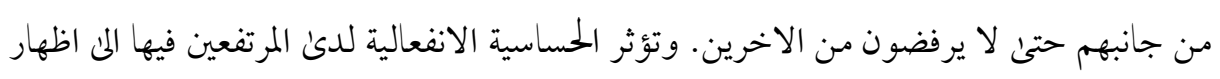

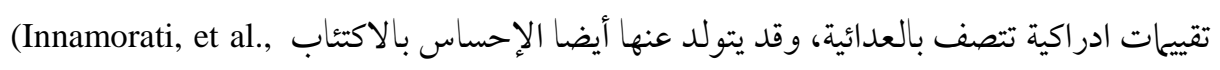
.2014, p. 1)

وتوضح (Barbieri, 2020) ان الافراد ذوي الحساسية الانفعالية يتصرفون عادة بأسلوب

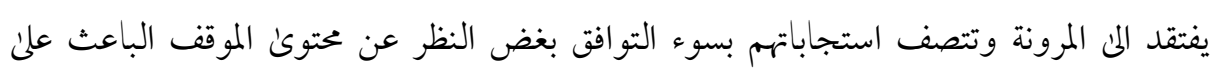

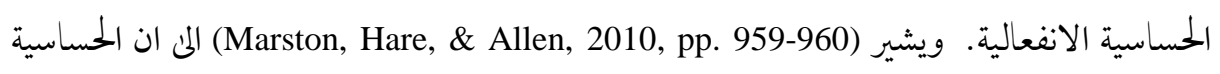

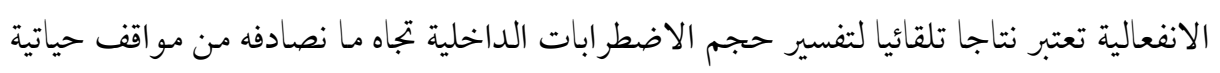

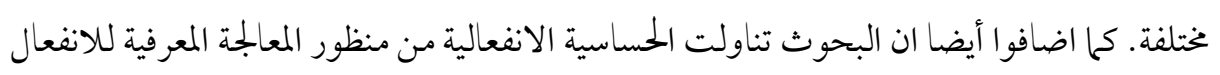

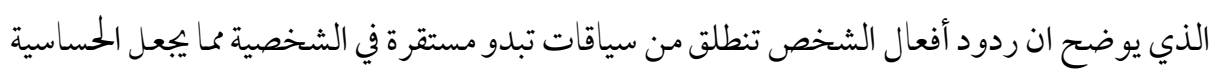

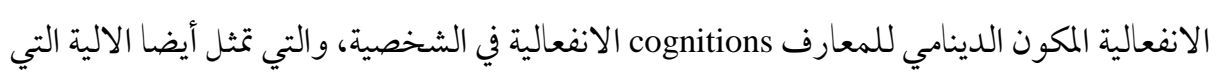

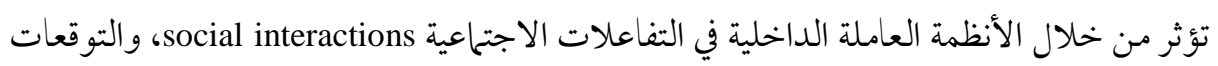
فان بexpectancies فان مـا يحدث خلال مو اقف الحساسية الانفعالية ان تنشط التوقعات السلبية بصورة الية وتلقائية مما 
يجعل الأشخاص المرتفعين في الحساسية الانفعالية قراءة مشهد الرفض من الاخرين بصورة سريعة، وتصرفهم حياها دفاعيا. ويشير (Perdighe, et al., 2015, p. 349) ان مفهوم الحساسية الانفعالية يرتبط بتقييات الفرد السلبية لحالته الانفعالية، وتمتد لتشمل كل الخبرات الانفعالية الجديدة التي لميمر بها من قبل ـ ومنذ اعمار مبكرة، فان الكائنات البشرية تعمل علن تشكيل رأيها عن المسببات، ولغة الجسد، والجوانب المعرفية، والمؤشرات النفسية المميزة للانفعالات وفق خبراتهم الذاتية من ناحية والتأثيرات التي تحدث داخليا جراء هذه الانفعالات من ناحية أخرىن، لذا تعتبر الانفعالات مصدرا للتهديد على استمتاعهم بجودة الحياة. وتعتبر الحساسية الانفعالية أحد مظاهر الاضطر ابات الانفعالية التي قد تعتبر مؤشر اعن إصابة الفرد بالقلق والاكتئاب. ونظر الان الادراك الانفعالي يعتمد أساسا علئ العمليات النفسية المعقدة الا أنه يتوقف من خلال الاضطرابات الانفعالية كالقلق والتقدم في العمر (Rutter, Scheuer, Vahia, . Forester, \& Germine, 2019)

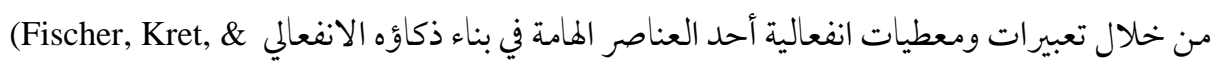
.Broekens, 2018, p. 1) وتذكر (Barbieri, 2020, p. 4) أنه بالتشابه مع الحساسية الانفعالية، فان الخوف من التقييم السلبي قد يؤثر أيضا علن إدراك الفرد لانفعالاته. ويعتبر الخوف من التقييم السلبي نوعامن القلق الاجتحاعي الذي يتكون من ثلاث عوامل: الخوف من تقييم الاخرين، توقع التقييمات السلبية، والاحساس بالضغط النفيي نتيجة للتقييمات السلبية؛ وجميعها تقود المن التجنب avoidance للتقييمات السلبية. وهذه المكونات تناظر ما يناظرها في الحساسية الانفعالية تجاه الرفض من الاخرين: توقع القلق، سهولة إدراك الرفض والمبالغة غير المتو افقة في ردود الفعل، رغم انه لا يوجد جذع مشترك ينطلق منه المتغيرين: الحساسية الانفعالية، والخوف من التقييات السلبية.

ويذكر (Leticia \& Feldman, 2005) بعدين اساسيين للشخصية الحساسة انفعاليا هما الحساسية الفردية السالبة، والحساسية الموجبة للأقران، ثم أضافا بعدا ثالثا هو التباعد الانفعلي 
emotional distance الغضب و اليأس والعدوانية والانتقاد الحاد عند مواجهة مو اقف ضاغطة نفسيا عليها في البيئة المحيطة بها، ويقود بها في النهاية المى العزلة النفسية وفقدان الامل مما يدفعهم لأساليب توافق سلبية مثل تعاطي المخدرات. وتشير الحساسية الإيجابية تجاه الاقران للميل الانفعالي في إنشاءعلاقات مع الاقران والتأكيد علن قدرتهم في فهم انفعالات الاخر والتعاطف معه خاصة أصحاب المواقف الصعبة وهو ما يقود في النهاية الما الإحساس بالسعادة والنجاح الشخصي والاجتماعي. اما الابتعاد الانفعالي فانه يصف ميل الفرد لتجنب الاخرين بهدف تفادي الحساسية الانفعالية خاصة الذين لهم أوضاع صعبة او سيئة (ابو

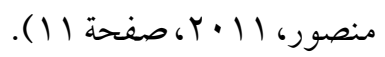
ويختلف معدل انتشار القلق والاكتئاب من مجتمع لأخر الا انه يمكن القول ان معدل انتشار

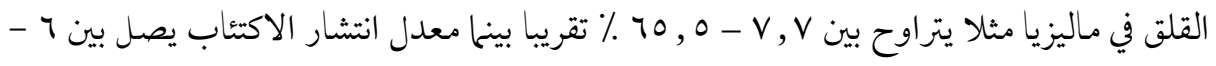

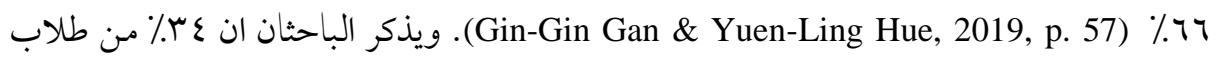
الطب في ماليزيا بالجامعات الخاصة قد عانو امن القلق في حين ع ٪٪ من هؤلاء الطلاب يعانون من الاكتئاب.

هذا، ولقد ارتبطت المستويات المرتفعة من سمة القلق بالقصور في المعالجة الانفعالية خاصة الحساسية الانفعالية المرتبطة بملامح الخوف المرتبط بالرفض من (Atwood, et al., 2017) الاخرين، بينما ان سرعة إدراك الخطر قد تكون ذات فائدة توافقية الا إذا تم ادراكها بطريقة خاطئة . وتعتبر جودة الحياة (Atwood, et al., 2017, p. 2) و اللازمة لتقييم الحالة الصحية والنفسية للفرد نظر الحساسيته الانفعالية كمتغير في التأثر بكل من القلق والاكتئاب، كما انه يتأثر بالضغوط النفسية والاجهاد ,Gin-Gin Gan \& Yuen-Ling Hue, 2019)

وتذكر (Kraines, Kelberer, \& Wells, 2018, p. 31) أن الاضطر ابات الانفعالية مثل القلق والاكتئاب تمثل عبئا على موازنة الصحة بالولايات المتحدة الامريكية بسبب ارتفاع نسبة شيوعها في 
المجتمع الأمريكي التي تصل النى ه , 1 \%٪، وما تسببه من شبه شلل في حياة الافر اد الذين يمثلون زهرة الإنتاج من الاعمار 0 -عـع سنة، لذا تعتبر الاضطرابات الانفعالية أحد الاهتمامات والتحديات الكبيرة في الو لايات المتحدة الامريكية. ولعل أحد الوسائل في أسلوب التعامل مع هذه الاضطرابات هو تحديد العو امـل ذات التأثير المباشر في انتاجها والتي اتفقت كثير من النظريات عليها وهي أنماط سوء التو افق الاجتماعي تلك التي تعتبر البيئة الحاضنة للاضطر ابات الانفعالية. وتعتبر الحساسية الانفعالية من أهم مكونات هذه البيئة الحاضنة، وهذا ما قد أوضحه الباحثون (Downey \& Feldman, 1996)، أن الخوف من الرفض وعرضه الحساسية الانفعالية، والخوف من التقييم السلبي (Coyne, 1976) وعرضه ردود الفعل السالبة، من العوامل المسببة للاضطر ابات الانفعالية.

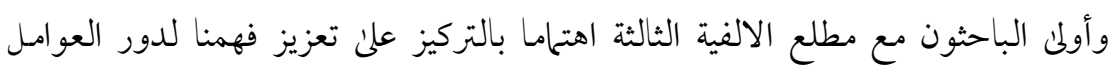

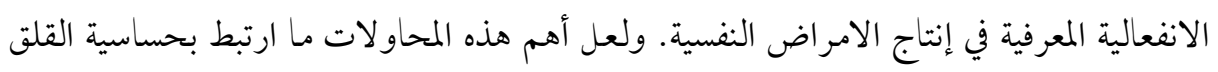
anxiety sensitivity والتي تشير المي الاستقرار النسبي للخوف من القلق وما يرتبط به. ولعل ما يميز الأفراد المرتفعين في حساسية القلق انهم أكثر عرضة للإحساس بالخوف الشديد خلال نوبات القلق بسبب معتقداتهم الداخلية ان حساسية القلق لها عو اقب ضارة سواء علن الجانب النفسي او الاجتهاعي

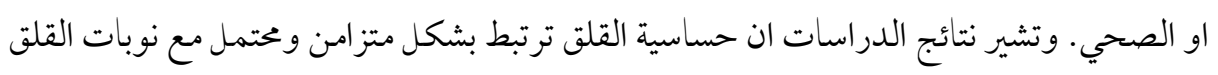
الشديدة بالإضافة لبعض الامراض النفسية الأخرى كالاكتئاب، وان تأثيراته تفوق سمة القلق لدئ الفرد نظرا لكونه الجانب المعرفي لانفعال الخوف من القلق \&utz, Marshall, Bernstein, \& (Rutter, Scheuer, Vahia, Forester, \& ويتفق هذا وما ذكره.Zvolensky, 2010, p. 16) ان الباحثين بذلو اعلن مدئ الأربعين عامـا الأخيرة محاو لات لفهم العلاقة بين الاضطرابات الانفعالية مثل القلق واضطرابات المزاج والمتغيرات المعرفية والادراكية والانفعالية. ويتساءل (Quimet, Kane, \& Tutino, 2016) إذا كانت حساسية القلق تعبر عن الخوف من القلق خاصة ام هو الخوف من الانفعالات عامة؟ وييبب الباحثون ان حساسية القلق ترتبط بصورة غير مباشرة بالأعراض الاكتئابية والقلق عبر بوابة تنظيم الانفعالات.

\section{http://dx.doi.org/10.29009/ijres.4.2.2}


ويشير (Perdighe, et al., 2015, p. 350) أنه يمكن التعامل مع الانفعالات كمصدر للتهديد الداخلي للفرد، فإذا كان الانفعال يمثل نوعا من التهديد فان الفرد يحاول امـا تجنب هذا الانفعال او احتواءه بالجانب المعرفي وحل مصدره وسببه. ويعتبر القلق خير النهاذج علن ذلك، فالفرد الذي يعاني

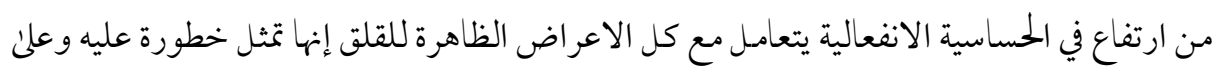
صحته وبالتالي فان الفرد يستشعر القلق نظرا لان تقييمه للأعر اض قد أثارت انفعالات وردود أفعال اما انها تقو ده للأسو أ او علن الأقل تحافظ علن مستوى الاعر اض الحالية الا انها لا تساعد في اختفاءها. وتوضح (Fischer, Kret, \& Broekens, 2018, p. 1) ثمة فروق بين الجنسين في الحساسية

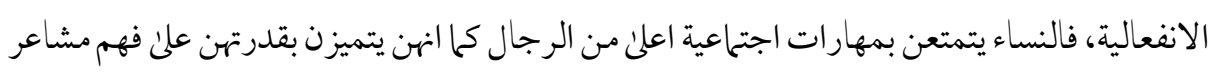
الاخرين بسهولة أكبر من الرجال، ودعم هذا الاعتقاد لديها نتائج عددمن البحوث ان درجات الاناث علن مقياس الذكاء الانفعالي والتعاطف الانفعالي كانت أعلن من نظيرتها لدئ الرجال، الا أن الأفراد الذين يعانون من القلق العام في شخصيتهم يظهرون قصورا واضحا في معالجة انفعالاتهم وان كانت

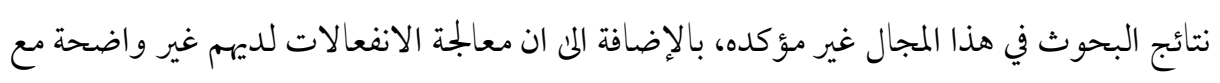
مرور الوقت. كما ان الفروق بين الجنسين في جودة الحياة تبدو لصالح الاناث في عمر المراهقة حيث ليث تصل قمة جاذبيتهن بينما تكون لصالح الرجال في مرحلة منتصف العمر حيث يحققون مكانتهم

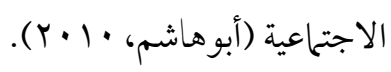

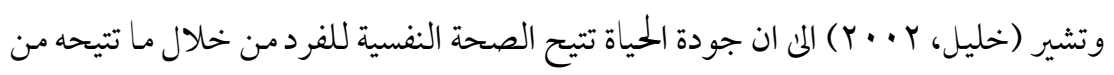
اشباع للحاجة المى الامن التي تحدث عنها ماسلو، فالأشخاص الذين يتمتعون بجودة الحياة متفائلون وسعداء ومبدعون في أعمالهم وعلاقاتهم الاجتماعية.

ولعل قراءة المعلومات حول أفكار الاخرين ومشاعرهم ونواياهم تعتبر من ركائز التفاعل الاجتماعي الناجح حتى أنه اضحى في وقت من الأوقات أحد متطلبات القيادة الناجحة، واحد مظاهر التعبير عن الرضا في الحياة الاجتماعية (Fischer, Kret, \& Broekens, 2018) . 
وتذكر (Barbieri, 2020, p. 1) أن الافر اد الذين يتم تحديدهم أنهم حساسون انفعاليا هم أكثر عرضة للاختلال الوظيفي في علاقاتهم الشخصية عن ذويهم الأقل عرضة في الحساسية من الرفض مما يتطلب منهم تعلم أساليب مبتكرة في تفاعلاتهم لتجنب الرفض الانفعلي. وكما هو الحال في استراتيجية القتال او الهروب fight or flight عندما يشعر الفرد المرتفع في الحساسية من الرفض للتهديد الواقع عليه فانه يصبح يقظا أكثر من ذي قبل لأي تهديد مستقبلي، وغالبا ما يدرك علامات للرفض من الاخرين حتى وان كانت غير موجودة بالفعل مما يؤدي بدوره المي المبالغة في ردة فعله، والتأثير السلبي

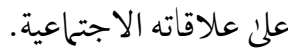

ولقد أوضحت نتائج البحوث ان هناك تأثير كبير للقلق الهائم في الشخصية علن العمليات الانفعالية إلا أن هذا التأثير قد يكون غير متفق عليه. فقد أشارت نتائج بعض البحوث المى العلاقة بين (Atwood, et al., ارتفاع القلق الهائم في الشخصية وانخفاض القدرة على توليد الاستجابة الانفعالية (2017، وبين الاهتمام الانتقائي للتهديدات، حيث أظهرت النتائج ان الافر اد الذين يعانون من القلق الهائم يعانون من قصور في تحديد استجاباتهم الانفعالية بمعنى انهم قد تسبق انفعالاتهم تفكيرهم و ادر اكهم بالمقارنة مع غير القلقين (Bui, Anderson, Goetter, Campbell, \& Barrett, 2017) . كما (Surcinelli, ارتبطت سمة القلق المرتفعة بالقدرة علن التعرف المانملامح الخوف في وجوه الاخرين meta-analysis كما ان تذليل المحتوي ضعف العزو . Codispoti, \& Montebarocci, 2006) الانفعالي لملامح الوجه أوضحت ان البالغين الذين يعانون من اضطرابات القلق يظهرون ضعفا متوسطا في التعرف علنم ملامح انفعالات الوجه وان كانت هذه النتائج لتحليل المحتوى أوضحت ان الأطفال الذين يعانون من اضطراب القلق لا يعانون بصفة عامة من صعوبة تعرفهم علن الانفعالات

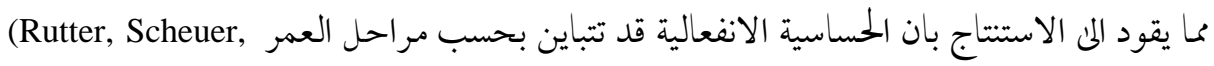
. Vahia, Forester, \& Germine, 2019) ويشير (Guarino, 2003) إلى أن العصابية تشير الني جملة الانفعالات السالبة لأثر الحساسية الانفعالية في ظهورها. وتعتبر العصابية Neuroticism (N) واحدة من سمات الشخصية التي تشرح في 
درجتها العليا ان الفرد يعاني من تقلبات مزاجية بالإضافة المي معاناته من القلق والحوف والاحساس

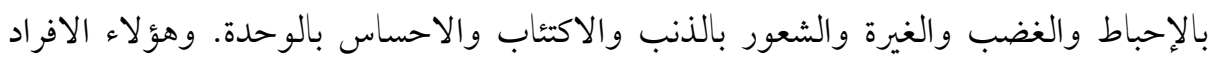

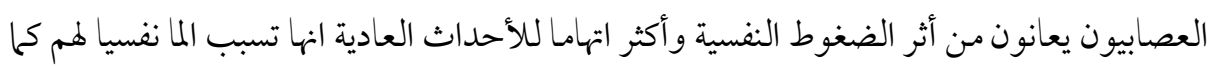
ان الاحباطات الطفيفة تعني ان المواقف قد أصبحت ميؤوس منها. وقدم (Downey \& Feldman, 1996) نموذجا أطلقا عليه قيمة توقع قلق الرفض إنس expectancy-value of anxious expectations of rejections نتيجة للتفاعل بين قلق الرفض rejection anxiety وتوقع الرفض expectancy of rejection، وقامـا

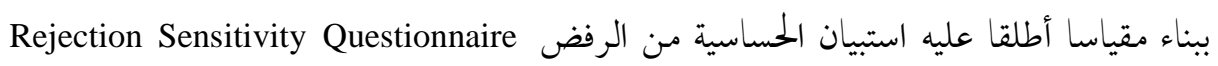

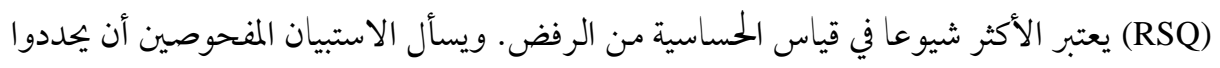

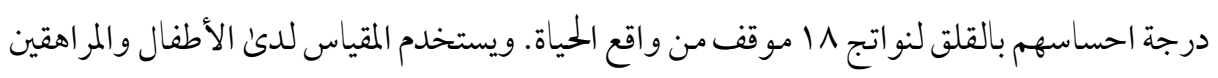
والراشدين بالرغم من ان صياغة المواقف في الاستبيان الأصلي كانت خصصصة للطلاب الجمامعيين.

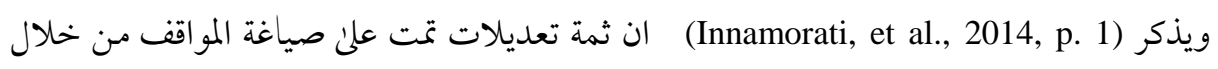

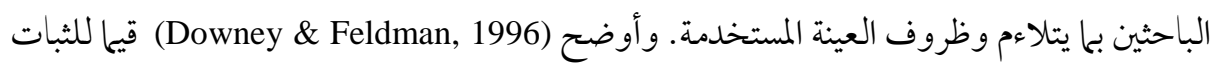

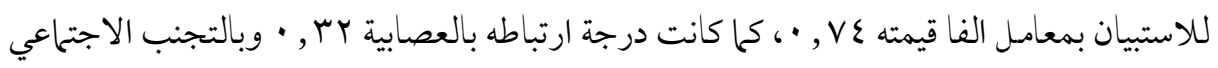

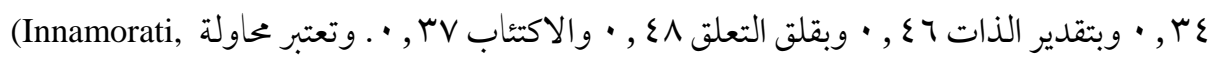

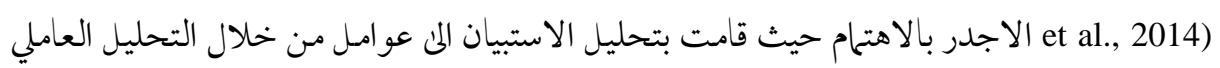

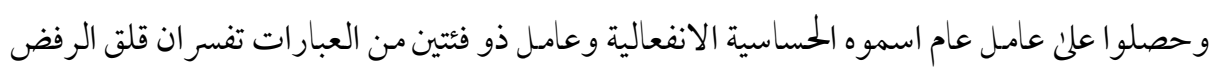
وتوقع الرفض. وفسر العامل العام ع \& من قيمة التباين في الأداء علني الاستبيان.

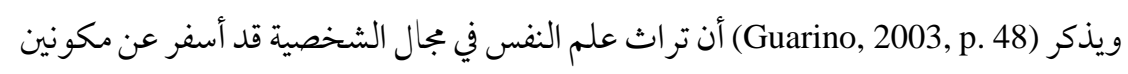
رئيسيين هما الانبساطية (Extraversion (E) والعصابية Neuroticism وهذان المكونان للشخصية

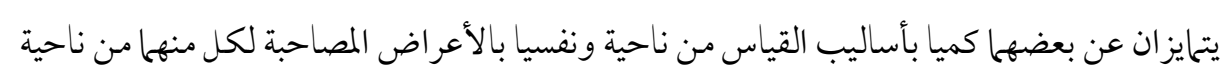

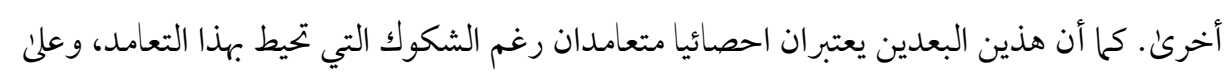


سبيل المثال فان بعد الانبساط الانطواء في النسخة الاصلية لمقياس ايزنك للشخصية عام ع197 والمعروف باسم Eysenck Personality Inventory (EPI) دمبج فيها بين الاندفاعية impulsiveness والقابلية الاجتماعية sociability الا انه في النسخة التي صدرت منه للمقياس عام 9 ا 19,والمعروف باسم Eysenck Personality Questionnaire (EPQ) فصل عبار ات الاندفاعية وضمنها في مقياس فرعي جديد هو الذهان .Psychotics ويذكر أيضا (p.48) ان العصابية تتكون من ابعاد فرعية مختلفة بعضها عن بعض في نسختي المقياس EPI \& EPQ بالإضافة المى ان ابعاد العصابية الكمية في المقياسين ليست واحدة. وتأكد هذا من ظهور عاملين مستقلين للعصابية في نسخة المقياس EPI هما الحساسية sensitivity والتوهم hypochondriasis بعدد 19 مفردة من جملة المفردات ع r للعصابية. وأشارت نتائج التحليل العاملي لنسخة المقياس EPQ ان بعد العصابية يتكون من بعدين هما الحساسية الانفعالية ومتغير اخر أطلق عليه المزاجية \&oger \& Morris, 1991; Roger \& moodiness (Guarino, 2003, p. 49) تجارب أخرى للتحليل العاملي لمقياس (Nesshoever,1987) الشخصية إعداد ايزنك وان جميعها توصلت لنتائج مشابهه بالإضافة المن ان التحليل العاملي للمقياس ككل فسر 9 , 1 1٪ من التباين كأقصئ قيمة توصلت اليها نتائجه حتى ان العوامل التي ظهرت من

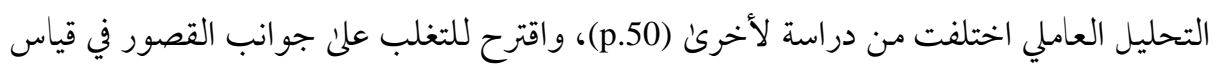
سمات الشخصية باستخدام مقياسي ايزنك هو تعديل التركيب البنائي للمقياس من خلال ضم كل من

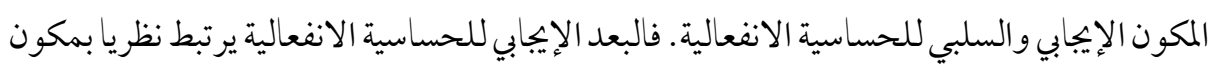
التعاطف empathy حيث ان الفروق الفردية يمكن ان تكون نوعا من الحساسية الانفعالية والتي تمثل العتبة الفارقة لدئ البشر كي يتعرفوا علن الانفعالات الأساسية في ذواتهم او ذوات الاخرين (51).

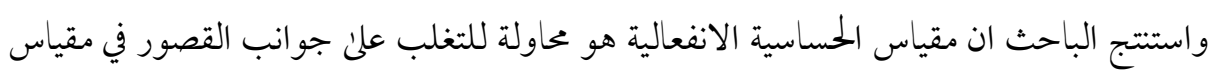
العصابية او عدم الاستقرار الانفعلي. وقد أتاح مقياس الحساسية الانفعالية ردود فعل انفعالية أكبر بما تهدف المن قياسه من انفعالات سلبية وأخرىن إيجابية للحساسية الانفعالية. ويقيس البعد السلبي للحساسية الانفعالية the Negative Emotional Sensitivity (NES) تهدف لتحديد ميل الفرد ان

\section{http://dx.doi.org/10.29009/ijres.4.2.2}


the Positive يعبر عن تجاربه الذاتية الانفعالية السالبة، بينما البعد الإيجابي للحساسية الانفعالية Emotional Sensitivity Scale (PES)

والتعاطف معهم (Guarino, 2003, p. 62)

ويذكر (Lebois, et al., 2020) أن الشفاء من اضطراب الهوية الفصامي dissociative)

يتطلب عمليات تكامل علاجية تهدف النى بناء التماسك الداخلي للذات identity disorder (DID) emotion بالإضافة الما القدرة في تملك السيطرة علن الجوانب الانفعالية. ويعتبر إدراك الانفعالات perception بناء يقوم أساسا علن التفاعل بين الجو انب المعرفية المخزونة في صورة خبرات سابقة للفرد،

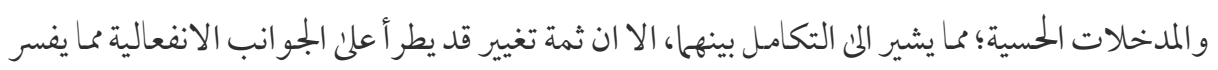
بعد هذا التكامل عن وضعه الطبيعي. وافترض الباحثون انه كلما كان التكامل في مستويات مرتفعة كلما كانت الاعر اض النفسية السلبية في اقل درجة ها، وهذا ما حاول الباحثون التحقق منه في دراستهم على عينة من Y N اشترط فيهم أنهم تعرضوا لصدمة انفعالية سابقة بالإضافة لتشخيصهم انهم يعانون من ون اضطراب الهوية الانفصامي. واستخدم الباحثون مقياسا للإدراك الانفعالي يعتمد على قراءة وفهم تعبيرات انفعالية لملامح الوجه. و اعتمد الباحثون علن افتراض أن التكامل المرتفع بين الادراك الانفعالي وما يراه الفرد بعينه يتوقف على درجة دقة إدراك هذا الفرد لانفعالات الوجه المعروضة عليه. وأشارت

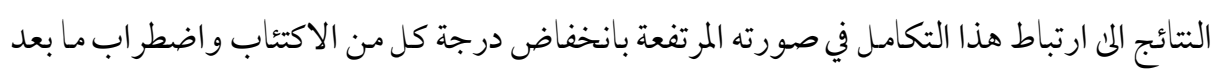
الصدمة والتشويش الناتج عن الخو اطر الشخصية autobiographical memory كما أظهرت النتائج ان التكامل المرتفع ارتبط بدقة قراء الانفعالات للوجه في حالة الخوف والغضب. وثمة نماذج معرفية للاضطر ابات الانفعالية تتصف بأن القلق يعتبر فيها تهديدا عالي التأثير، ويتضمن هذا النموذج الانتباه الاختياري selective attention، وصعوبة فك الارتباط مع مصدر المعلومات ذات التهديد. بالإضافة المى ذلك الارتباط بين القلق المرضي مع ضعف القدرة علن التعرف

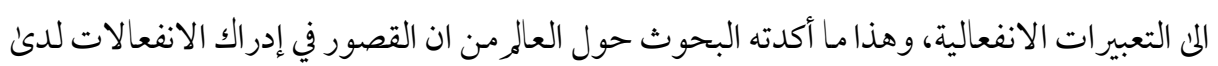


حالات تعاني من القلق المرضي. وهناك أيضا نتائج تشير المن إدراك مرتفع جدا للوجوه المخيفة لدني الأفراد المرتفعين في مستويات القلق (Atwood, et al., 2017, p. 2).

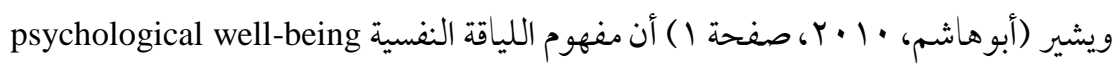
يعتبر من المفاهيم الرئيسة في بجال علم النفس الإيجابي وهو قريب في المعنى من جودة الحياة والذي يشير المى شعور الفرد بالسعادة والرضا من أجل تحقيق معنى للحياة وتحقيق أهدافه وقيمه الخاصة التي هي نتاج قدرته علن النمو والتطور الصحيح ليصبح وجوده بالحياة ميزا ومتميزا عن الاخرين. ويوضح أيضا ان المفاهيم مثل الشعور بالراحة النفسية، الرضا عن الحياة، المتعة في الحياة، التوافق النفسي،

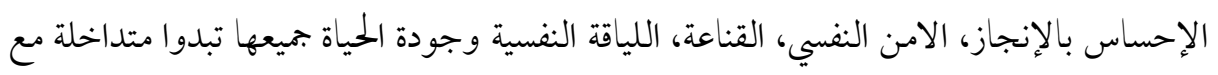
بعضها البعض. ويذكر (Gao \& McLellan, 2018, p. 1) أن مفهوم جودة الحياة قد لاقئ قبو لا من الباحثين في دراسته ببعض المتغيرات مثل القلق والاكتئاب ومفهوم الذات كتعبير عن مدى تمتع الفرد بالصحة العقلية mental health. ويشير الباحثان أيضا إلى أن جودة الحياة هو مصطلح يمثل مظلة لجملة من المتغيرات ولا يمكن التعامل معه كمتغير مستقل في حد ذاته مما يزيد من صعوبة فهمه وتعقيده كمصطلح، إلا أن المتخصصين في بجال علم النفس تعاملو امع المصطلح كمؤشر للأداء النفيي الأفضل وكتعبير عن درجة النضج في خبرات الحياة اليومية للفرد. ويستطرد الباحثان ان هناك نمطين فلسفيين لتفسير جودة الحياة أحدهما داخلي hedonism باعث على الإحساس بالسعادة بينما الاخر خارجي eudemonism الذي يبحث عن المعزئ من الحياة. ويقصد (Ryff, Spring, \& Loive, 2004, p. 246) باللياقة النفسية شأنها شأن جودة الحياة تتكون من أبنية متعددة الابعاد تعكس تقييمات الافر اد لأنفسهم ونوعية حياتهم وفق ستة عو امل : تقبل الذات pelf-acceptance، العلاقات الإيجابية مع الاخرين positive relationships with others،

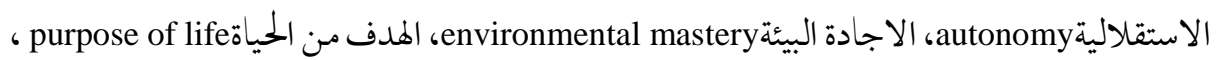
النمو الشخصي personal growth. 
ويذكر (Pontin, Schwannauer, Tai, \& Kinderman, 2013, p. 1) ان مصطلح جودة الحياة هو أحد المتغيرات النفسية متعددة الابعاد ذات وظائف إنسانية. ويمكن تعريف جودة الحياة بأنها حالة يكون الفرد فيها قادرا علن تطوير طاقاته، يعمل بإنتاجية وابتكارية أكبر، له شبكة من العلاقات

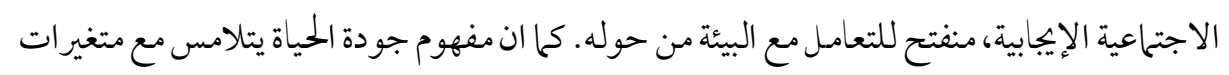

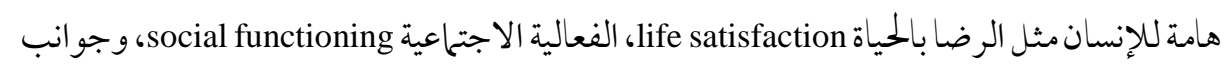
عملية أخرىن الجودة الحياة. ويوضح (الربابعة، IV · Y أن مصطلح جودة الحياة يشمل الجو انب الإيجابية في حياة الفرد، وتبرز أهميته في تحسين جودة الحياة كمنطلق للصحة النفسية للفرد. وهناك مؤشرات لتحديدها تتمثل في المؤشرات النفسية التي تفسر إحساس الفرد بالقلق والاكتئاب او شعوره بالرضا والسعادة؛ المؤشرات الاجتماعية التي تفسر شبكة العلاقات الاجتماعية مع الاخرين ونشاطات الفرد الترفيهية و الاجتماعية؛ والمؤشرات المهنية التي تفسر رضا الفرد عن مهنته وقدر اته في تنفيذ ما يو كل اليه من اعمال، والمؤشرات الجسمية التي توضح مدئ تمتع الفرد بالصحة الجسمية العامة والنوم الطبيعي وقدرته الجنسية؛ وأن من بين محددات جودة الحياة الذاتية حيث كونها انبساطية في مقابل الانطو ائية، عصابية في مقابل الاتزان الانفعالي، التفاؤل في مقابل التشاؤم، تقدير الذات ووجهة الضبط. كما ان جودة الحياة تشمل المجال النفسي للفرد الذي يعتمد علن غياب المؤثرات السلبية كالقلق والاكتئاب. ويشير (Pontin, Schwannauer, Tai, \& Kinderman, 2013) إلى أنه ينبغي عند الحديث عن جودة الحياة الذاتية، الفصل بينها وبين العوامل الخـارجية التي تؤثر عليها مثل العوامل المادية كالبيت الذي يعيش فيه الفرد، والعوامل المادية كقيمة الدخل الشهري له؛ فجودة الحياة الذاتية هي ما يقرره الفرد من خلال تقييمه لبيئته التي يعيش فيها، استجاباته في المو اقف المختلفة، وانعكاس خبرات حياته

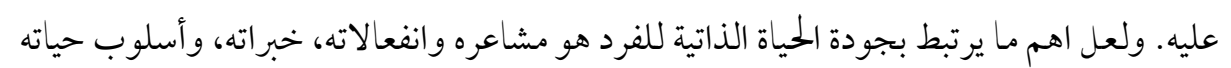
عامة؛ بالإضافة المى ما حققه تعليميا، وتقييمه لصحته العامة، وما حققه من نجاحات مهنية. ولابد 
للإشارة ان هناك بجموعة من المؤشرات الموضوعية تفشل في ان تأخذ بعين الاعتبار الادراك الإنساني human perception الذي يعتبر أساسيا في فهم جودة الحياة.

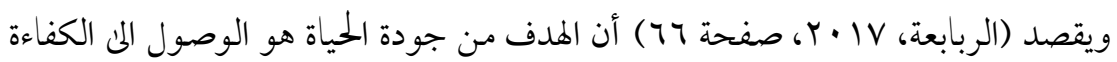
والنجاح في الحياة والشعور بالرضا والسعادة والمسئولية الشخصية والاجتماعية، كما يقصد بها شعور

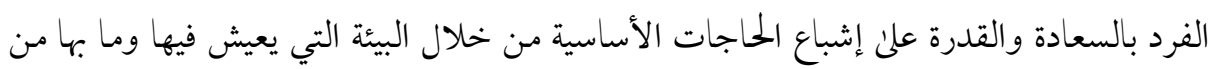
خدمات صحية وتعليمية ونفسية مع قدرة الفرد علن إدارة الوقت والاستفادة منه. وتذكر (داهم، 0 • r، صفحة بr) تعريفا لمنظمة الصحة العالمية لجودة الحياة أنها مفهوم واسع يتأثر بشكل معقد بكل من الصحة الجسمية للفرد، حالته النفسية، علاقاته الاجتماعية، مستوى تحكمه في ذاته، بالإضافة الما علاقاته مع العو امل الفعالة ببيئته. وتشير أيضا ان جودة الحياة هي قضية الانماء في الأساس أي نمو الانسان وفق مستويات الصحة النفسية الإيجابية. كما أنها تعني أيضا الدرجة التي يجد

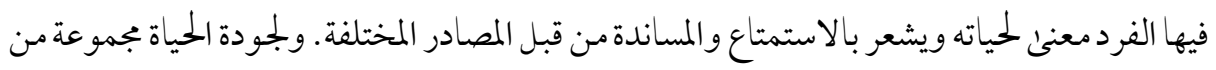
الابعاد تتمثل في التقدير الذاتي للرضا عن الحياة بوجه عام، التقرير الذاتي للرضا في مجالات العمل و الصحة والعلاقات الاجتماعية مع الاخرين، والمؤشرات الاجتماعية وما يصادفه فيها من عوائق.

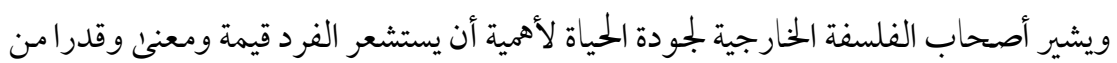
الإنجاز في حياته؛ مما جعل (Ryff, 1989) تقترح نموذجا بنائيا افتراضيا يتكون من ست عناصر تشكل جميعها بناء لمفهوم جودة الحياة. وتتضمن هذه المكونات الحكم الذاتي autonomy، التمكن البيئي penvironmental mastery العلاقات الإيجابية مع الاخرين positive relations، وقبول الذات self-acceptance. ولقد اقترح وهو من أصحاب البعد الداخلي لجودة الحياة، نموذجا بنائيا لتحديد جودة الحياة (Diener E. , 2000) الذاتية subjective well-being (SWB والذي يتكون من تقييمات الفرد المعرفية والانفعالية لحياته. واعتبر ان الإحساس بالسعادة هو إحساس عابر للثقافات رغم ما بينها من تناقضات واختلافات. 
وعند الحديث عن اللياقة النفسية، ميز (Gregory \& Brinkman, 2015, p. 12) بين نمطين نظريين يعتبران الأساس لفهمها: hedonic and eudemonic wellbeing وتشير أصحاب المدخل الذاتي للياقة النفسية hedonic wellbeing إلى التركيز علن الخبرات الذاتية للسعادة وتتكون من : الحكمي

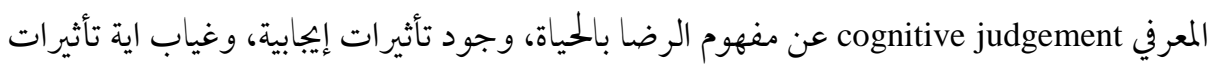

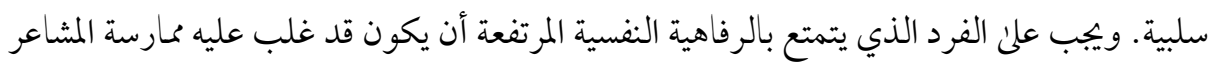

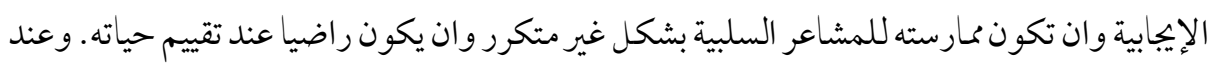

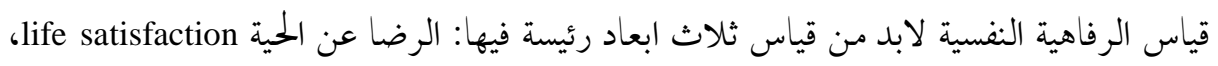

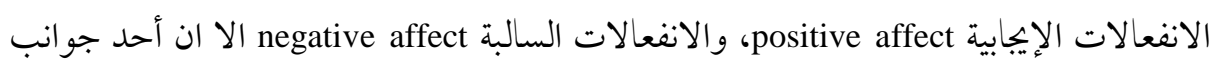
القصور في اللياقة النفسية الذاتية هو ان السلوكيات غير المتكيفة مثل إساءة استخدام المخدرات من

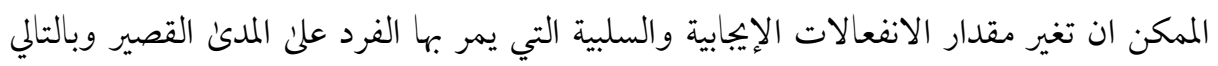

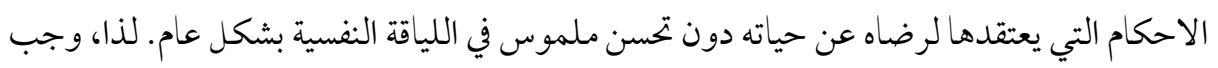

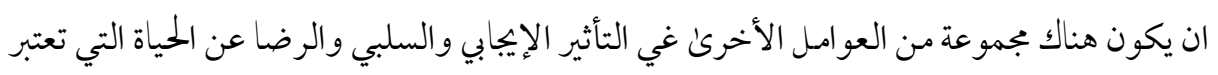

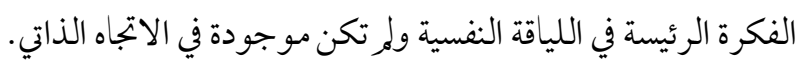

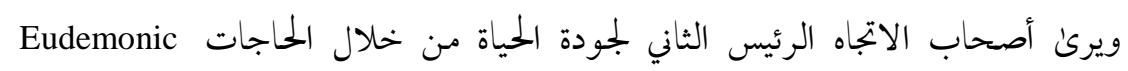
wellbeing في جودة الحياة انها لا ينبغي ان تركز عن السعادة بقدر ما التركيز عن الحاجات الإنسات الإنسانية. والفكرة هنا هي ان البشر لديهم حاجات needs رئيسة مثل الشعور بالمعنى في حياتهم، والاستقلال

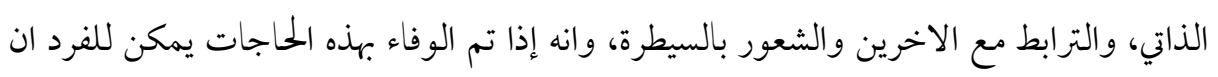

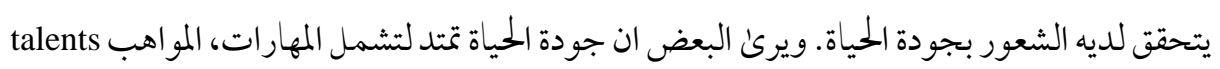

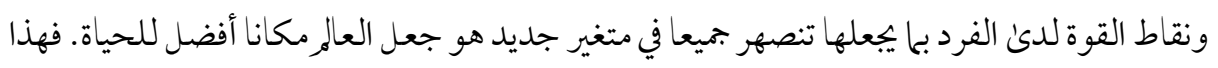

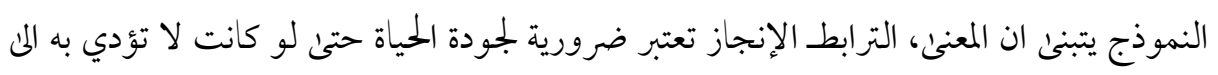

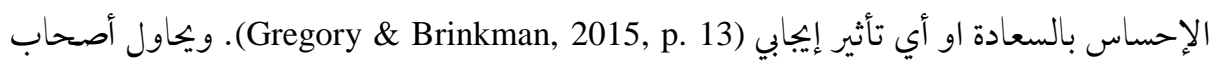

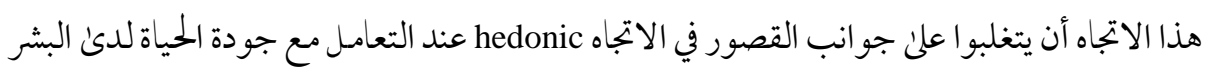


(Seligman, 2011). ووضع سيلجحان نموذجا من خمس مكونات للرفاهية النفسية أطلق عليه positive emotion حيث يشير كل حرف لمكون من المكونات الخمسة: الانفعالات الإيجابية PERMA

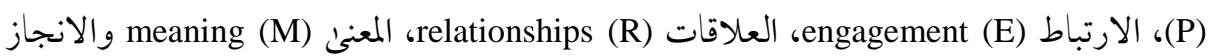
accomplishment (A) بحا يصلح لقياسها لدى المراهقين والراشدين، وأطلق عليه نموذج EPOCH الذ يشير كل حرف منه لاحد مكونات النموذج: الانغهاس (E) (engagement، المثابرة (P) (P) التفؤل coptimism (O) ان المكونات الثلاث (P, R, E) يمكن ان تكون مشتركة في الرفاهية النفسية لكل مراحل العمر من طفولة ومراهقة ورشد الا ان المعنى (M) قوالانجاز(A) قد لا يكون لهم) نفس المعنى لدى كل من الأطفال والمراهقين وتم استبدالهما في النموذج الجديد بالتفاؤل (O) Optimism والمثابرة . perseverance $(\mathrm{P})$ ويرى (Pontin, Schwannauer, Tai, \& Kinderman, 2013, p. 2) ان الميدان مليء بأدوات قياس اللياقة النفسية وجودة الحياة والعوامل المرتبطة بها بالرغم من ان هذه الأدوات تميل نحو معالجة جوانب معينة من جودة الحياة. وتشير (Algahtani, 2020, p. 39) ان جودة الحياة تتأثر بعددمن العواملل أهمها درجة نمو كل موده من المخ والجانب الاجتهاعي، وهما المسؤولان عن تقلب المزاج لدئ الفرد؛ وان نمو المخ هو المسؤول أيضا عن استجابة الفرد للمثيرات المحيطة به في البيئة. و كلما كان الجانب الاجتماعي أسرع كلم) ظهرت اثاره على الإحساس بجودة الحياة.

ويذكر (Huppert, 2009) ان هناك مجموعة من الإيجابيات في الإحساس بجودة الحياة positive feelings of quality of life في العلاقات الاجتماعية. وذهب أيضا المي ان دائرة الانفعال بالمخ غاية في التعقيد خاصة قشرة الفص الجبهي التي، خلافا لأغلب مناطق الدماغ الأخرى التي تهتم بمعالجة الانفعالات، بها في ذلك قشرة 
الفص الجبهي والنواة اللوزية وقشرة الفص القشري الامامية وقشرة الفص الجبهي؛ لذا فان مناطق الدماغ الأخرى ليست بنفس تعقيد الفص الجبهي. وهذه المكونات من الدماغ تعمل جميعا في انتاج الاستجابة الانفعالية والتي نشاهدها في السلوك. ويتصف الافراد المتمتعين بالرفاهية النفسية لديهم مستويات عليا من نشاط الجزء الايسر اثناء الراحة عكس الذين يعانون من جودة الحياة. ويوضح (عبد الوهاب و شند، • ( · ) عشرة أبعاد للحياة الجيدة أجملها في: التفاعل بإيجابية،

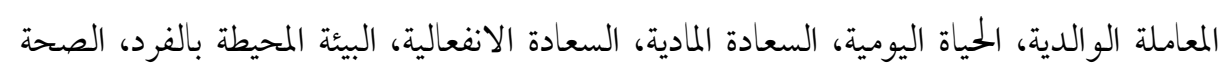
العامة، السعادة الاجتماعية، والإنتاجية؛ كما تتأثر بعدد من العوامل منها السلامة البدنية، الشعور بالأمن، الشعور بالقيمة والجدارة الشخصية، وتنظيم الحياة، الإحساس بالانتحاء للأخرين، والتفاعل الاجتحاعي، والرضا والشعور بالسعادة داخليا؛ كما انه لا يوجد ترتيب هرمي لهذه الابعاد، فكل فرد يرتبها وفق ذاتيته بالنسبة لجودة حياته الشخصية. ويمكن تقسيم جودة الحياة المي الجودة الذاتية التي ترتبط بالفرد ذاته ورؤيته للحياة، وجودة الحياة الوجودية حيث تكون الحياة الجيدة في اعلى مستوياتها. ويوضح (Pontin, Schwannauer, Tai, \& Kinderman, 2013) ان مقياس هيئة الإذاعة البريطانية للرفاهية النفسية BBC Subjective Well-being Scale (BBC-SWB هو استبيان تم بناؤه لقياس الخبرات الذاتية للأفراد من خلال ابعاد متعددة هي ما يتكون منها مصطلح الرفاهية النفسية.

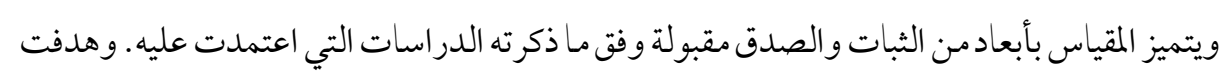
الدراسة الما بناء معايير جديدة للثبات والصدق لهذه الأداة من خلال نسخة جديدة ومنقحة باستخدام تدريج للاستجابات حماسي يختلف عما كانت عليه النسخة الاصلية للمقياس رباعي الاستجابة. وأعاد الباحثون بناء المقياس في صورة ثلاث ابعاد للرفاهية النفسية هي: المكون النفسي، والبدني، والعلاقات الاجتماعية. واستخدم الباحثون عينة قوامها ا ع سبr بأسلوب الانترنت. وقام الباحثون بتطبيق بطارية

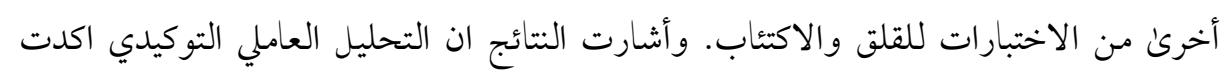

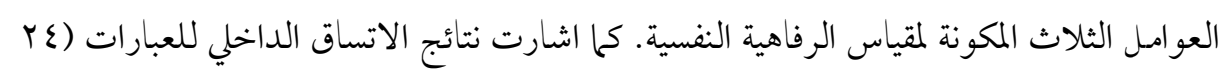
عبارة) و المقاييس الفرعية (ثلاث مقاييس) نتائج مقبولة لتؤكد الصدق البنائي للمقياس. 


\section{مشكلة الدراسة وتساؤلاتها}

$$
\text { تحاول الدراسة الحالية التحقق من التساؤلات التالية: }
$$

ا. ما درجة شيوع كل من الحساسية الانفعالية، القلق، الاكتئاب، وجودة الحياة لدئ طلاب لئل

\section{الجحامعة}

r. هل توجد علاقة ارتباطية ذات دلالة إحصائية بين جودة الحياة وكل من الحساسية الانفعالية،

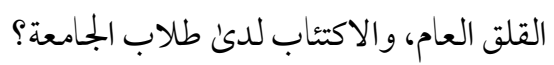

r.هل توجد فروق ذات دلالة إحصائية في متغيرات الدراسة: الحساسية الانفعالية، القلق،

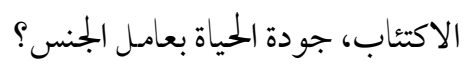

ع. هل توجد فروق ذات دلالة احصائية في كل من جودة الحياة والحساسية الانفعالية بمستويات

$$
\text { كل من القلق العام والاكتئاب لدني طلاب الجامعة؟ }
$$

ه. هل يمكن التنبؤ بجودة الحياة من المتغيرات المستقلة: الحساسية الانفعالية، القلق، الاكتئاب؟

$$
\text { أهداف الدراسة: - n - n }
$$

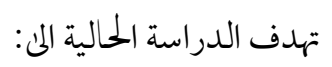

ا. التعرف علن درجة شيوع الحساسية الانفعالية، القلق، الاكتئاب، وجودة الحياة لدىن طلاب

$$
\text { الجلامعة }
$$

r. التعرف علن العلاقة الارتباطية بين متغيرات الدراسة: الحساسية الانفعالية، القلق، الاكتئاب،

$$
\text { وجودة الحياة لدئ طلاب الجامعة }
$$

r. التعرف على الفروق في متغيرات الدراسة: الحساسية الانفعالية، القلق، الاكتئاب لدئ طلاب

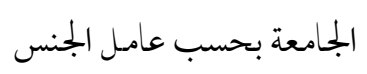

ع. التعرف علن الفروق في كل من جودة الحياة والحساسية الانفعالية بمستويات كل من القلق

$$
\text { العام والاكتئاب لدئ طلاب الجامعة. }
$$

\section{http://dx.doi.org/10.29009/ijres.4.2.2}


0. التبؤ بجودة الحياة لدى طلاب الجامعة من خلال المتغيرات المستقلة الحساسية الانفعالية،

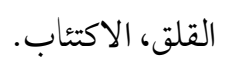

\section{دراسات سابقة}

هدفت الدراسة التي قام بها (Guarino, 2003) إلى محاولة فهم العصابية ومكو ناتها من خلال

بناء مقياس للحساسية الانفعالية يمكن الاعتماد عليه في تقليص الدور المحتمل للحساسية الانفعالية في انتاج أعر اض نفسية مضطربة من ناحية وتحفيف الإحساس الناشئ عن العصابية من ناحية أخرىن. واعتمدت الدراسة علن عينة قوامها • rV طالب جامعي من جامعة York، وقام ببناء مقياسه Emotional للحساسية الانفعالية. وأوضحت نتائج التحليل العاملي لمقياس الحساسية الانفعالية Sensitivity Scale (ESS) ويمثل الاخر الجانب السلبي ها (other-oriented) العاملي المتعامد عاملين لما درجة عالية من التناسق الداخلي، أطلق عليها التفاعل البين شخصي الإيجابي negative egocentric positive interpersonal sensitivity العاملي التوكيدي. وقد أشار الباحث المن ان أحد معايير صدق الأداة الجحديدة من خلال افتراضه ان ردود الفعل العالية للأفراد ذوي التفاعلات البين شخصية الايجابية تظهر عند مواجهتهم بمصادر للضغوط النفسية، وهنا يمكن التعرف علن مشاعرهم و أحاسيسهم. وذكر الباحث أيضا أن التأثيرات

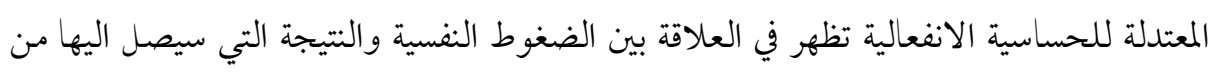
المرض النفسي. ولقد أوضحت النتائج ان الحساسية السلبية تعتبر من اقوىن المنبئات في اختبارات التقرير الذاتي للأفراد عن حالاتهم البدنية والنفسية. كما اشارت النتائج ان الحساسية الإيجابية ليس لها تأثير مباشر علن الصحة العامة بقدر ما يظهر دورها في الوقاية من الوقوع فريسة للضغوط النفسية الناجمة عن سوء استراتيجيات التوافق. واستتج الباحث ان هذه النتائج للحساسية الانفعالية يمكنها ان تفيد 
البشرية من خلال بعديها الإيجابي والسلبي اللذان يرتبطان بالجوانب المختلفة للصحة العامة وإيجابية التكيف النفسي. وهدفت الدراسة الطولية التي قام بها (Marston, Hare, \& Allen, 2010) إلى التعرف على دور الحساسية من الرفض علن النمو الانفعلي والاجتماعي في مرحلة المراهقة المتأخرة. ويذكر الباحثون ان الحساسية من الرفض ترتبط بكل من الاكتئاب و القلق لدئ الشباب في مرحلة المراهقة المتأخرة، كما انها ترتبط بضعف الكفاءة الاجتماعية والانفعالية لديهم. كما ان الذكور من المراهقين أبدوا درجة من الحساسية من الرفض أكبر منها لدئ الاناث المراهقات. وتم تفسير النتائج في ضوء أهمية الحساسية من الرفض في فهم النمو الانفعالي والاجتحاعي في فترة المراهقة المتأخرة. وهدف (Diener, et al., 2010) إلى قياس اللياقة النفسية من خلال مقياسين أحدهما للازدهار flourishing من 919 من طلاب الجامعة من ست مناطق نختلفة. وتكون مقياس اللياقة النفسية من ثمان مفردات تقيس مدى' استجابة الفرد لمدئ النجاح الذي يشعر به في بعض من مكونات حياته مثل العلاقات الاجتماعية، تقدير الذات، الغائية من الحياة، والتفاؤل. ويقيس المقياس درجة كلية للازدهار النفسي. ويقول الباحثون ان المقياس يتمتع بقيم ثبات وصدق مقبولة. ويتكون مقياس كل من المشاعر الإيهابية و السلبية من 7 مفردات. وهذا المقياس كما يشير الباحثون أيضا يتمتع بقيم مقبولة للثبات والصدق. ويقول الباحثون ان مقياس الانفعالات الإيجابية-السلبية يقيس مدنئ واسع من الانفعالات التي مر بها الفرد خلال الأسابيع الأربعة الأخيرة.

وانطلق (Jovev, et al., 2011) من الافتراض بأن اضطراب الشخصية الحدية borderline personality disorder عادة لديهم توقعات دقيقة من خلال التعبيرات الانفعالية في مر احلها المبكرة؛ بمعنى ان عتبة الإحساس الفارقة لقراءة الانفعالات لديهم تكون عادة مرتفعة. واعتمد الباحثون في دراستهم علن عينة قو امها ا Y من الشباب (10 - ع سنة) من العيادات النفسية الخارجية تم تشخيصهم انهم يعانون من اضراب

\section{http://dx.doi.org/10.29009/ijres.4.2.2}


الشخصية الحدية وفق محكات التشخيص بدليل التشخيص الر ابع لجمعية علم النفس الامريكية - التشية حيث اشارت النتائج ان هؤلاء الافراد اوضحوا حساسية مرتفعة تجاه ملامح وتعبيرات انفعال IV الوجه مقارنة بالمجموعة الضابطة.

وهدفت الدراسة التي قام بها (Innamorati, et al., 2014) إلى التعرف علنى الصدق البنائي لمقياس الحساسية من الرفض للراشدين، حيث استخدم الباحثون طريقة التقرير الذاتي علن بنود المقياس بالإضافة لمقاييس الاكتئاب والقلق واليأس. اعتمدت الدراسة علن عينة قو امها ع VV من الر اشدين في إيطاليا أعمارهم بين 11 - عا سنة حيث أشارت لنتائج التحليل العاملي لوجود عاملين أحدهما عام و أطلق عليه الباحثون عامل الحساسية الانفعالية العام بالإضافة لعامل ذو بجموعتين هما توقع الرفض sexpectancy of rejection كما أظهرت النتائج ارتباط العوامل بعضها مع بعض. كما حصلت الدراسة على نتائج للثبات مقبولة. واستتج الباحثون ان الصدق البنائي للمقياس قد تحقق، وان البعدين: قلق الرفض وتوقع الرفض قد يدعان الفرد في تحقيق الرفض له وان اختلفت الطرق في ذلك. وهدف (أبو شمالة، IV P إلم التعرف علنى ان كان مفهوم الذات يمكن ان يكون عاملا وسيطا بين الانفعالية الحساسية والتو جه نحو الحياة للطلبة ذوي الإعاقة السمعية. واعتمدت الدراسة علن عينة من المعاقين سمعيا الملتحقين بالجامعة في غزة قوامها ـ م طالب وطالبة. وأوضحت النتائج أن إدارة الذات لما علاقة مباشرة مع التوجه نحو الحياة بمعنى كلما زادت إدارة الذات كان التوجه نحو الحياة

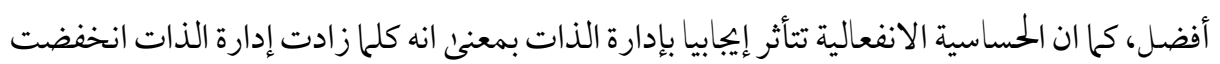
الحساسية الانفعالية، كما ظهرت علاقة ارتباطية سالبة دالة بين التوجه نحو الحياة والحساسية الانفعالية. و انطلقت الدراسة التي قام بها (Gao \& McLellan, 2018) من أن الرفاهية النفسية تعتبر نواة في الكثير من البحوث المتعلقة بالمر اهقين والراشدين. واعتمدت الدراسة علن مقياس الرفاهية النفسية the Scale of Psychological well-being (SPWB) للرفاهية النفسية ذو الابعاد الستة الذي قدم تصورا واطارا نظريا شاملا للمفهوم في تحديده الجوانب 
الإيجابية لدنى كل من المراهقين والراشدين. وهدفت الدراسة المى التأكد من ابعاد الثبات و الصدق لهذه الأداة نظرا لما اثير حوها من انتقادات في العديد من الدراسات السابقة خاصة لدئ الثقافة الصينية. و استخدمت الدراسة عينة قو امها VVY من المر اهقين الصينيين من الجنسين. وأشارت النتائج ان خمسا من الابعاد الستة المكونة للمقياس بينت معاملات تناسق داخلية مقبولة باستثناء بعد autonomy، كما أكدت نتائج التحليل العاملي انهالمتتوافق والنموذج النظري في حين ان من بين النماذج البنائية المقترحة كان النموذج البنائي سداسي الابعاد أفضلها علن الاطلاق. وأشارت النتائج وجود ارتباطات بينية عالية بين مكونات النموذج خاصة التمكن البيئي environmental mastering، الهدف من الحياة purpose تof life و والنضج الشخصي personal growth واستتج الباحثان صدق مـا توصل اليه من سبقاهما في تحديد ابعاد الثبات و الصدق لهذه الأداة. وعلل الباحثان ذلك بان العبار ات لم تكن مناسبة للعمر الزمني لعينة الدراسة. وهدفت الدراسة التي انطلق بها (Rutter, Scheuer, Vahia, Forester, \& Germine, 2019) بهدف التعرف علن العلاقة الارتباطية بين القلق الهائم والحساسية الانفعالية لانفعالات الوجه المعبرة

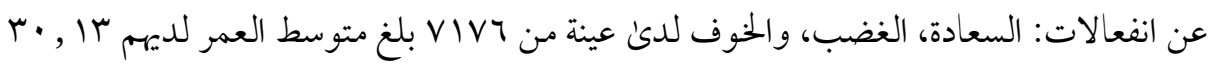
سنة بانحراف معياري rی, عا ـ واستخدم الباحثون مقياس القلق المكون من V عبارات تشير لأعراض القلق بالإضافة لمقياس Belmont emotion Sensitivity Test. وأشارت النتائج لوجود علاقة ارتباطية ذات دلالة إحصائية بين اعراض القلق والحساسية الانفعالية بعد ضبط كل من متغيري الجنس والعمر، مما يشير المي هذه العلاقة الارتباطية بين القلق والحساسية الانفعالية لا تتغير بعامل العمر. كما ان العمر كان منبئ للحساسية الانفعالية من اعر اض القلق الهائم حيث كانت الاعمار المتقدمة

$$
\text { اقل في الحساسية الانفعالية وأيضا اقل في الإحساس بأعراض القلق الهائم. }
$$

وهدفت الدراسة التي قامت بها (Usman \& Khan, 2019) إلى التعرف علي العلاقة بين الحساسية من الرفض rejection sensitivity وكل من الاكتئاب، تقدير الذات، وجودة الحياة لدى عينة قوامها • r ا فردا من الذكور الاناث المصابين بعقم الانجاب بلغ متوسط العمر فيها الو و • • عاما.

\section{http://dx.doi.org/10.29009/ijres.4.2.2}


واستخدمت الدراسة مقياس الحساسية من الرفض للر اشدين، ومقياس بيك للاكتئاب، مقياس مو اكبة الضغوط النفسية بالإضافة لمقياس Ferti Quality لجودة الحياة ومقياس Rosenberg لتقدير الذات. و أشارت النتائج وجود فروق دالة احصائيا في كل من الحساسية من الرفض، الاكتئاب، وجودة الحياة بعامل الجنس؛ في حين لم تظهر هذه الفروق في تقدير الذات. كما أظهرت النتائج فروقا دالة احصائيا بعامل الجنس في أساليب مو اجهة الضغوط النفسية. وأشارت النتائج ان الذكور كانو ا اعلن في متغيرات الحساسية من الرفض وأساليب مو اجهة الضغوط النفسية بينما الاناث كن اقل في الاكتئاب. هدفت الدراسة التي قامت بها (Barbieri, 2020) المي التعرف علني مدى ودقة تقييمات الافراد الذين يشعرون بالرفض لصحتهم الانفعالية. واستخدمت الدراسة عينة قوامها ل. ․

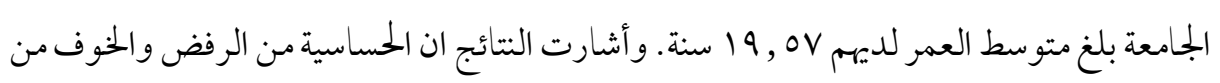
التقيم السلبي لم ينيئا بقدرتهم التعرف علن انفعالاتهم الا ان نتائج التفاعل لمتغير الخوف من التقييم

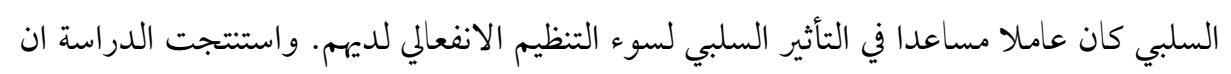
الخوف من التقييم السلبي قد يكون عاملا للحماية من التأثير السلبي لسوء التنظيم الانفعالي على دقة التعرف علئ الجانب الانفعالي لدئ الفرد الذي يعاني من الحساسية من الرفض الانفعالي.

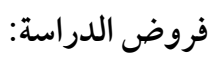

الفرض الأول: يتصف طلاب الجحامعة بالحساسية الانفعالية والقلق والاكتئاب.

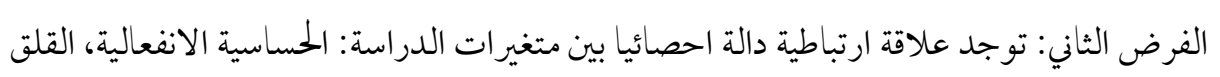

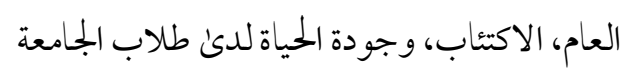
الفرض الثالث: توجد فروق ذات دلالة إحصائية بين متغيرات الدراسة: الحساسية الانفعالية، القلق

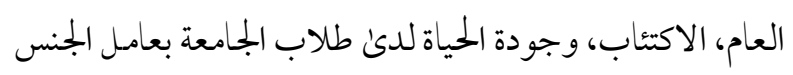

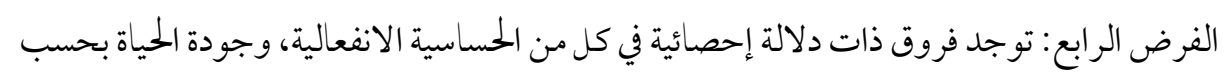

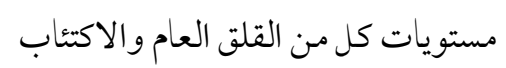


الفرض الخامس: تساهم المتغيرات المستقلة: الحساسية الانفعالية، القلق العام، الاكتئاب في التنبؤ بجودة الحياة لدئ طلاب الجامعة

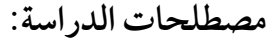

- الحساسية الانفعالية: emotional sensitivity هي ما يود الفرد القيام به من أنشطة في تفاعلات شخصية مع الاخرين وخوفه من الرفض منهم رغم رغبته التعاطف معهم. وسيتم قياسه اجر ائيا بالدرجة التي يحصل عليها الفرد بعد تطبيق مقياس (Guarino, 2003) تعريب الدراسة الحالية - - مeneral anxiety - مو حالة من عدم الاستقرار تنتاب الفرد جر اء الخوف من المستقبل، وسيتم قياسه اجرائيا بالدرجة التي يجصل عليها الفرد بعد تطبيق مقياس القلق العام Spitzer RL, Williams, \& Lowe, 1999) GAD-7) تعريب الدراسة الحالية. - م الاكتئاب: - depression - مالة من الحزن وفقدان الرغبة في الحياة واضطراب الفرد بها يعيق

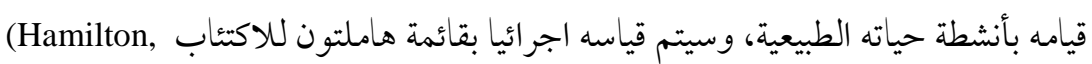

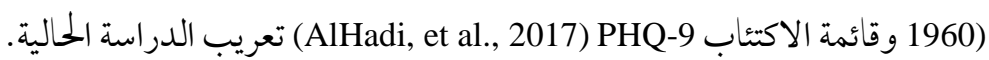

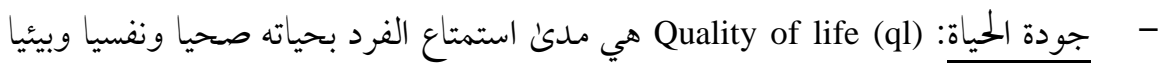
واجتماعيا، وسيتم قياسه اجرائيا باستخدام مقياس (WHOql) في صورته العربية الذي اعددته منظمة الصحة العالمية (WHOQOL, 1995).

الأهمية النظرية: تنطلق الأهمية النظرية للدراسة الحالية من أهمية المتغيرات التي تقوم بدراستها و أهمية المشكلة التي تبحث عن إجابة لتساؤ لاتها. وتعتبر المتغيرات التي تقو بدراستها عامة والحساسية الانفعالية خاصة على قدر عال من الأهمية في التعرف علن مدئ شيوعه بين طلاب الجامعة. كما أن العلاقة الارتباطية بين هذه المتغيرات مع بعضها البعض تعتبر في سياق جديد تحاول الدراسة من خلاله 
التعرف علن التفاعل فيما بينها بالنسبة لطلاب الجامعة خاصة فيا نعاني منه في زمن تتسارع فيه الاحداث والأزمات.

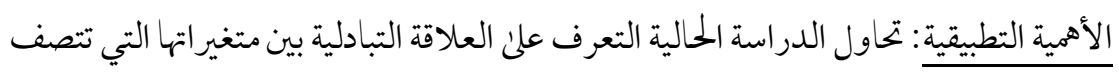

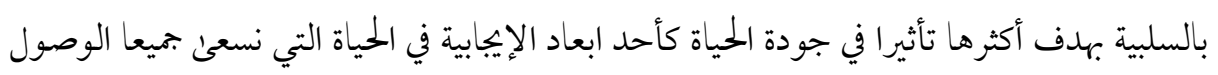

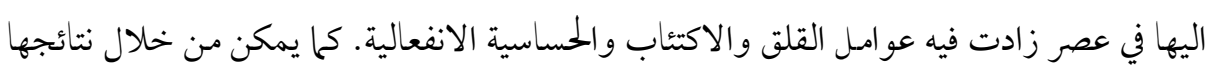

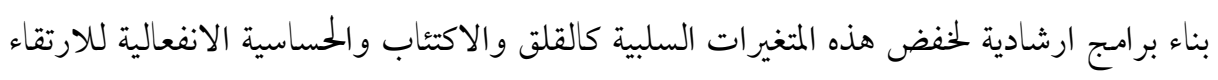
بجودة الحياة لدئ طلاي الجامعة شباب الحاضر رجال المستقبل.

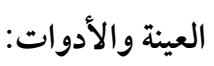

1. العينة: تعتمد الدراسة الحالية علئ عينة من طلاب الجامعة الدارسين بكلية التربية جامعة

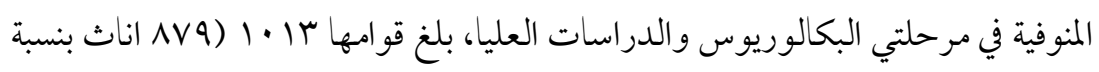

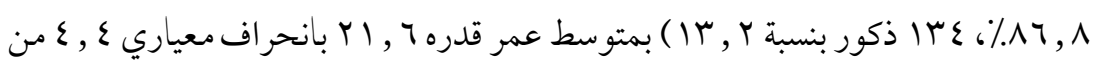

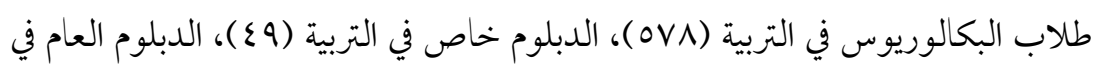

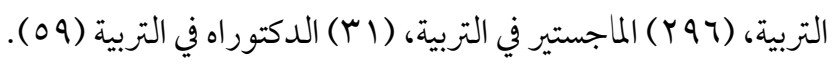

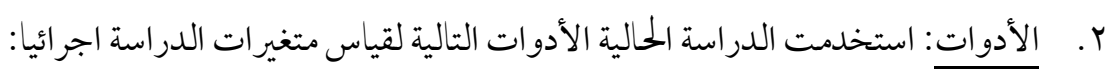

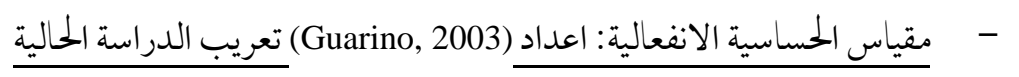

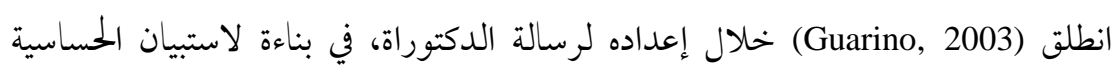

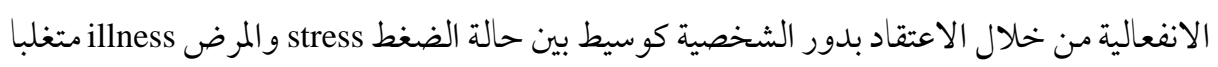
فيه عن جوانب القصور في بعض مقاييس ردود الأفعال الانفعالية خاصة مقاييس العصابية neuroticism

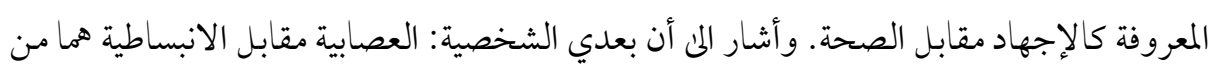

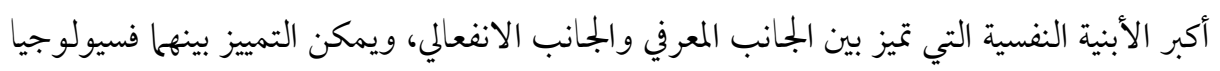

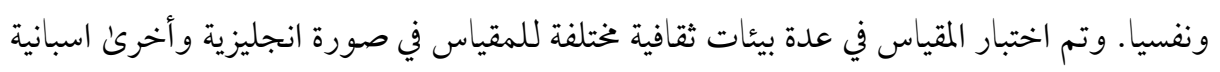

\section{http://dx.doi.org/10.29009/ijres.4.2.2}


وفنزويلية. وتتكون الأداة من بع عبارة يجاب عنها بنفس نظام الإجابة علن اختبار ايزنك للشخصية، المستقى النظري للمقياس، حيث تتكون الاستجابة من (ينطبق)، (لا ينطبق) . واعتبر الباحث ان تشكيل العصابية الانبساطية هو بناء متعامد في محورين، فان نتائج التحليل العاملي الاستكشافي لمقياس الحساسية الانفعالية أيضا أنتج بناء محوريا متعامدا من عاملين أحدهما إيجابي أطلق عليه الحساسية الانفعالية الموجهة نحو الاخرين other -oriented emotional sensitivity ويمثل الجانب الإيجابي في الحساسية الانفعالية ورمز ها positive interpersonal sensitivity (PIPS) بينما الأخر سلبي اطلق عليه الحساسية الانفعالية الموجهة نحو الذاتself-centered emotional sensitivity ورمز له negative emotional sensitivity (NES) والتصرف مع الاخرين بصورة سلبية. وتبين PIPS ميل الفرد ان يوجه انفعلاته نحو الاخرين، وقدرته التعرف علن انفعالات الاخرين، والاهتحام بها والتعاطف معها. ويتكون الجانب السلبي من 10 عبارة بينما يتكون الجانب الإيجابي من ^r عبارة. واظهرت نتائج التحليل العاملي للنسخة الاسبانية للمقياس وجود عامل ثالث أطلق عليه التباعد الانفعالي emotional distance وقصد به عدم رغبة الفرد الانخر اط في انفعالات الاخرين مع الإبقاء علنم مسافة بينه وبين الاخرين خاصة الذين يو اجهون نوعا

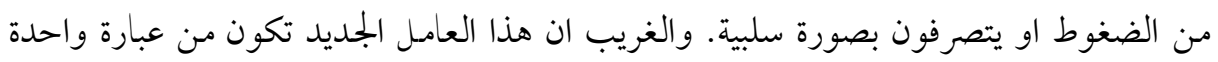
(اتجنب ان اتفاعل مع أي شخص يعاني ضغوطا او مو اقف صعبة) (Guarino, 2003, p. 234). ويتكون

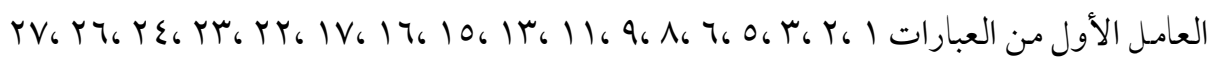

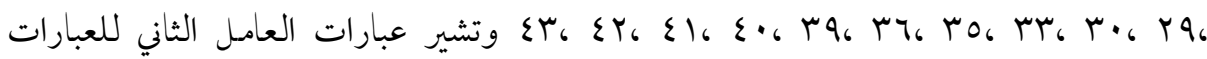
A N الانفعالية في الدراسة الحالية بدرجة كلية لمجموع ما يحصل عليه المفحوص من درجات علن عبارات المقياس. 
وأشار الباحث ان قيمة الفا كرونباك للعاملين مرتفعة حيث كانت قيمتها للعامل السلبي

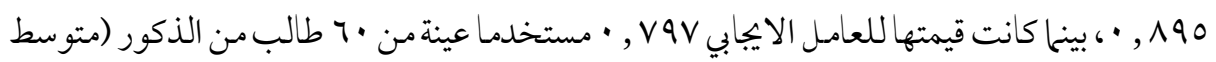

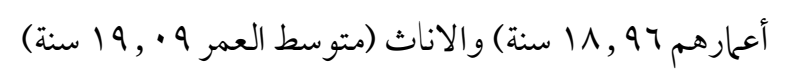

- مقياس اضطراب القلق العام general anxiety disorder (GAD) - مداد Spitzer) -

RL, Williams, \& Lowe, 1999)

تشير (Spitzer RL, Williams, \& Lowe, 1999) أن اضطراب القلق العام يعتبر أحد

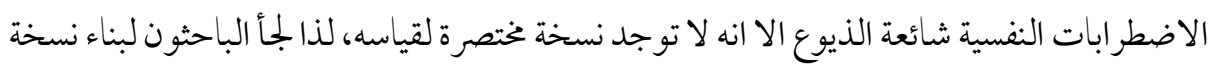

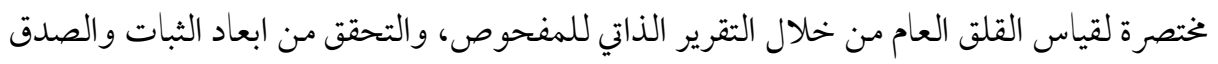

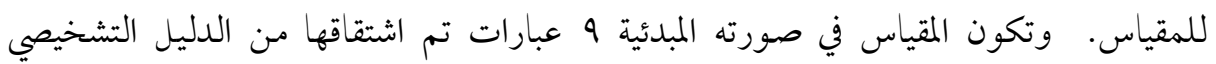

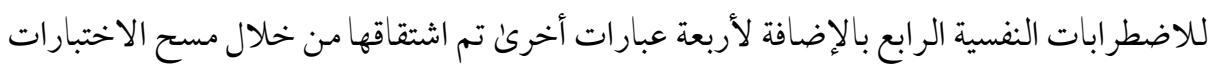

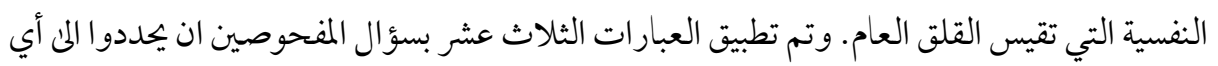

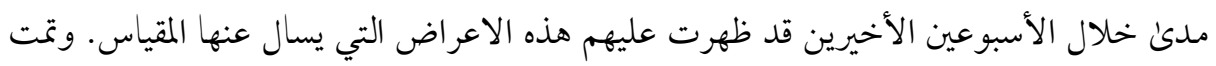

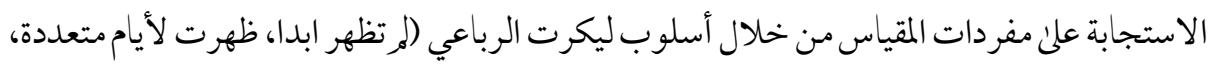

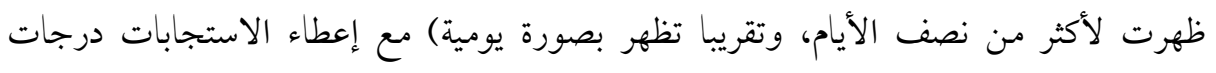

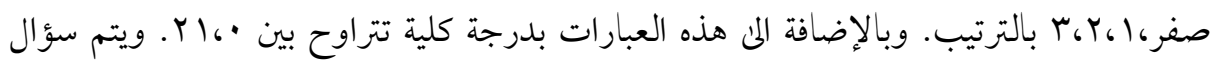

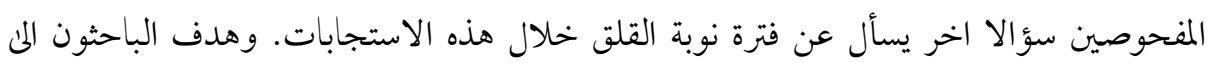

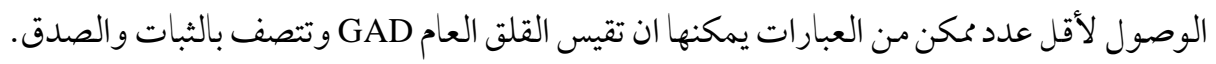

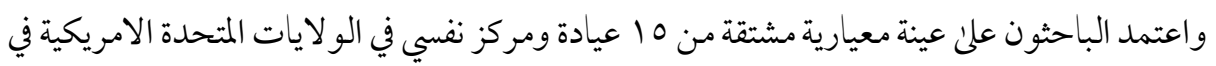

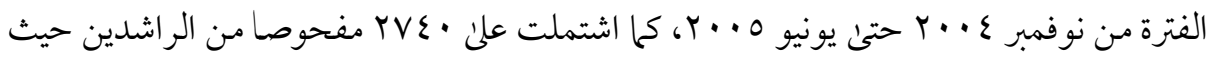

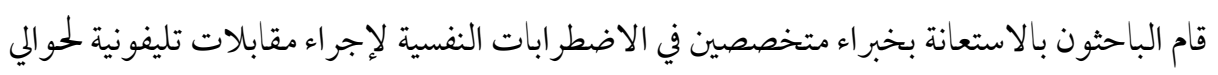
970 منهم. وتمت مقارنة التنائج التي تم التوصل اليها مع نتائج التشخيص الاكلينيكي المعتادة

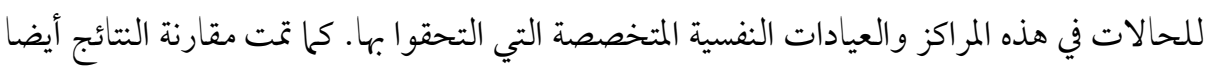

\section{http://dx.doi.org/10.29009/ijres.4.2.2}


بنتائج مقاييس الأداء، ونتائج أيام الإصابة بنوبات القلق، ونتائج الرعاية الصحية المقدمة للمفحوصين. وتوصل الباحثون المى الصيغة المختصرة لمقياس GAD الذي تكونت من V عبارات التي حصلت علئ قيم ارتباطية مع الدرجة الكلية للمقياس تراوحت بين (r=0.75-0.85)، اتصفت بثبات مرتفع بالإضافة لتمتعها بالصدق من خلال المحكات الخارجية والصدق العاملي. كما أشار الباحثون لاعتمادهم علئ محك لحساسية المقياس في تحديد GAD تراوح بين A9-19٪، كما أشارت الدرجات المرتفعة علة المقياس ارتباطا إيجابيا مرتفعا بدرجات المفحوصين علن اختبار قصور الأداء متعدد الابعاد. وبالرغم من الارتباط العام بين القلق والاكتئاب الا ان نتائج التحليل العاملي أظهرتها كعو امل مستقلة. كما أظهرت نتائج المقابلة التليفونية المتخصصة للمفحوصين ارتباطا مع درجاتهم علن المقياس. وأطلق الباحثون علن مقياسهم المختصر مقياس اضطراب القلق العام ذو السبعة عبارات GAD-7 واستتجوا انه صالح لتشخيص القلق العام في العيادات النفسية والبحوث العلمية.

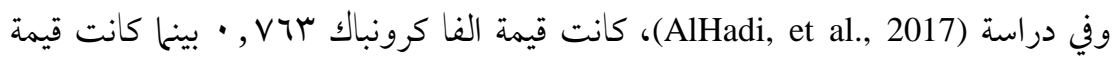
الاتساق الداخلي تتراوح بين ع • r , •-- ج ع , • في حين كانت معاملات الارتباط مع الدرجة الكلية

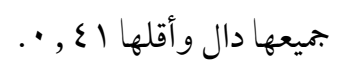
- قائمة هاملتون للاكتئاب اعداد (Hamilton, 1960) تعريب الباحث الحلالي هو أحد المقايس الإكلينيكية المعروفة في تشخيصها للاكتئاب، يعرف باسم Hamilton Depression Rating Scale (HDRS) الافر اد المكتئين داخل العيادات الاكلينيكية. ويتكون المقياس في صورته الحالية من Vا موقف تفسر

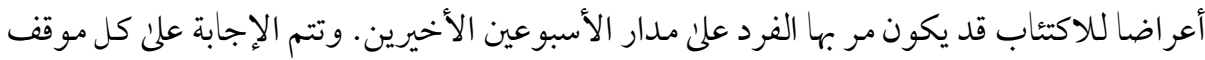

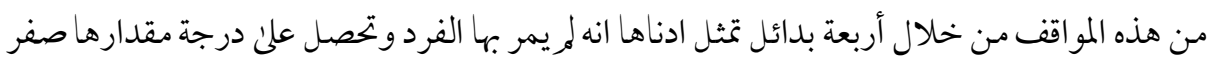
-r كأقصن قيمة حيث تحدث بصورة متكررة. وتتراوح درجات المقياس بين صفر - عه حيث تمثل الدرجة من صفر - ان الفرد طبيعي، 1-17 من المحتمل ان يكون مكتئبا بدرجة بسيطة، IV-IV مكتئب لدرجة متوسطة، بينما الدرجة §Y فأكثر تشير لاقتراب الفردمن حالة الاكتئاب، وهي نفس 
حدود التفسير لدرجات GAD-7. وقد ترجم المقياس الما الفرنسية والألمانية والإيطالية والتايلاندية و التركية، كما انه تم تطويره لعدة صور بدأت بالصورة الحالية (HDRS17) النىصور أخرىن. وقد ظهرت صور مكافئة للمقياس الأصلي منها (Patient Health Questionnaire (PHQ-9) الذي يتكون من 9 مواقف تبين حالة الاعراض التي يمكن من خلالها الاستدلال علن وجود اعراض للاكتئاب خلال الأسبوعين الأخيرين. وتتكون الاستجابة على كل موقف منها أربع استجابات تبدأ بغياب العرض (صفر) وتنتهي بتوغل العرض داخل الشخصية (r). ونظرا لان الصيغة العربية لمقياس هاملتون للاكتئاب غير متوفرة، فسوف تقوم الدراسة الحالية بتطبيق الاداتين بهدف التحقق من عامل الصدق في كلاهما. وأوضح (Carrozzino, Patierno, Fava, \& Guidi, 2020) ان عدد الاقتباسات التي تمت علئ مقياس هاملتون وصلت لرقم قياسي وفق Scopus التي اشارت الما وصوله اب ألف اقتباس مما يوحي انه على درجة عالية من الثقة في استخدامه لتشخيص الاكتئاب. كما أوضح الباحثون تحليلا لقيم الثبات والصدق في النسخ المختلفة للمقياس، وكلها كانت مرتفعة. وحدد الباحثون بين نسختين من المقياس: الأولن التي ظهرت دون تعليات والثانية التي ظهرت بتعليات محددة للمفحوصين، ومع مرور الزمن أنتج هامنلون عدة صور نت مقياسه التي تباينت في عدد مفرداتها وما تقوم بقياسه أيضا. وتوصل هاملتون في تشخيص الاكتئاب لعشرة حالات من خلال القائمة والاستعانة بخبيرين اكلينيكيين حيث توصل لمعامل اتفاق ع^ , · بينها، وكان معامل الارتباط لسبيرمان ع9 , · كمؤشر مرتفع لثبات القائمة. ويوضح (Carrozzino, Patierno, Fava, \& Guidi, 2020, p. 137) ان باحثين قد توصلو القيمة ثبات بلغت الو , · بينما تراوحت قيمتها بين 10 , · - 97 , · بطريقة إعادة التطبيق.

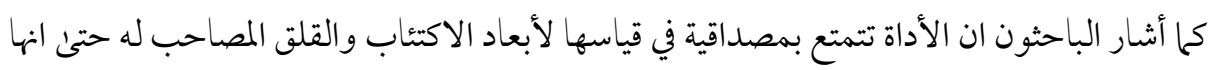
تغطي المضاعفات الجانبية لهما من اعراض اضطرابات الوزن وممارسة الجنس. كما ان الأداة تمكنت من تمييز الاكتئاب بين المصابين بالاكتئاب والعاديين.

كما ظهرت محاولة عربية لقياس ابعاد الثبات والصدق لمقياس PHQ-9 في البيئة السعودية.

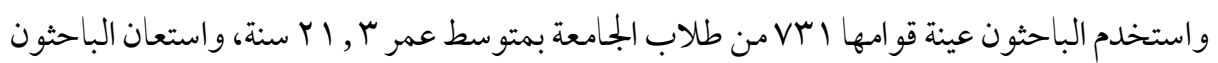


بثمانية من الخبراء الاكلينيكيين للتحقق من الصدق الظاهري للأداة في صورتها العربية. وأوضحت نتائج الثبات بمعامل الفا كرونباك قيمة 1 10V, •، كما اشارت قيم الارتباط بين العبارات والدرجة الكلية قيما ذات دلالة إحصائية كانت أقلها rVA , • ، و اظهرت قيم الاتساق الداخلي معاملات ارتباط

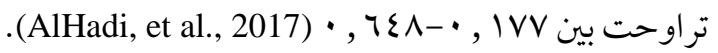
- مقياس منظمة الصحة العالمية المختصر لجودة الحياة

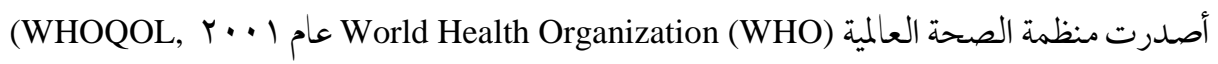
(1995مقياسا لجودة الحياة WHOQoL ، بكل لغات العالم منها العربية، في صورة مطولة (· . 1 عبارة) وصورة نختصرة (7 ب عبارة) في أربعة أبعاد لجودة الحياة هي: الصحة الجسمية physical ( ويتكون من V أجزاء تشمل الأشطة الحياتية اليومية، الاعتحاد على العقاقير والمساندة الطبية، الاجهاد، قابلية التحرك

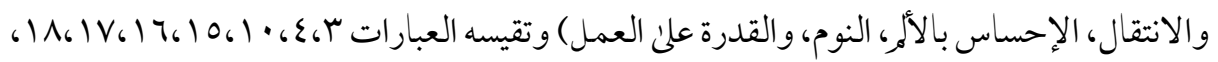
النفي psychological (ويتكون من ستة مجالات هي : صورة الجسم، المظهر العام، المشاعر السلبية، المشاعر الإيجابية، تقدير الذات self-esteem ، معتقدات الفرد الدينية، وابعاد التفكير والتعليم والتذكر

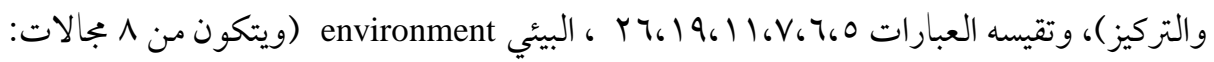
الموارد المالية، الحرية، الامن والأمان المادي، الرعاية الصحية والاجتماعية، الفرص المتاحة لاكتساب المعارف وتعلم المهارات، اتاحة الفرصة للأبداع والنشاط الترفيهي، البيئة الطبيعية ومشتملاتها التلوث

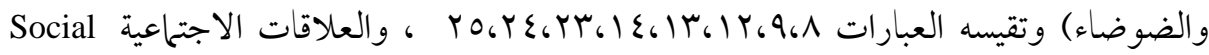
relationship (ويتكون من ثلاث بجالات هي العلاقات الاجتماعية الشخصية، المساندة الاجتماعية،

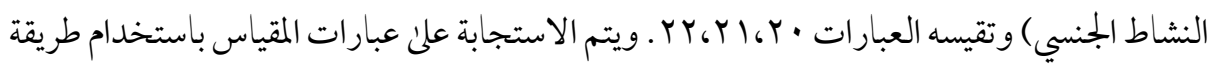
ليكرت خماسية الاستجابة حيث يطلب من المفحوص اختيار الإجابة التي تنطبق عليه امـام كل عبارة من بدائلها الخمسة. ويتكون المقياس من عبارات إيجابية تدل علن جودة الحياة هي العبارات 年

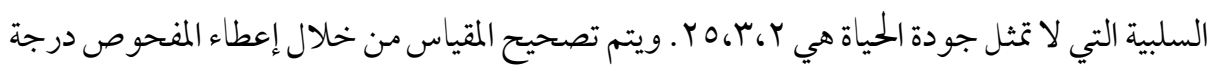

\section{http://dx.doi.org/10.29009/ijres.4.2.2}


تتراوح بين 1،0 في العبارات الإيجابية وعكسها في العبارات السلبية حيث كلما اقتربت الدرجة من ه

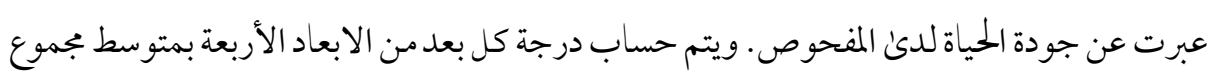
درجات المفحوص على عبارات هذا البعد، ويمكن حساب الدرجة الكلية من خلال جمع درجة

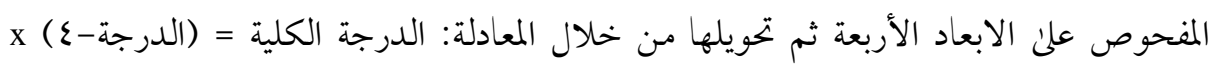

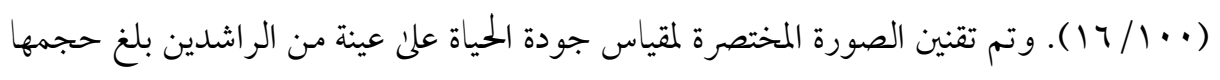
• الصحية، وقد وجدت معاملات ارتباط مرتفعة دالة احصائياً (من 19 , · فأكثر ) بين أبعاد الصورة المختصرة لمقياس جودة الحياة وأبعاد الصورة الكلية لنفس المقياس. كذلك تم التحقق من القدرة التمييزية لعبارات المقياس، وتمتعه بالصدق التمييزي وصدق المحتوي وبالاتساق الداخلي وبثبات إعادة الاختبار. هذا فضلاً علن أنه تم إعداد صور متعددة لهذا المقياس في العديد من بلدان العالم، والتحقق من ثباته وصدقه فقد تم إعداده للبيئة الكورية والماليزية والتايوانية والإيرانية والهندية

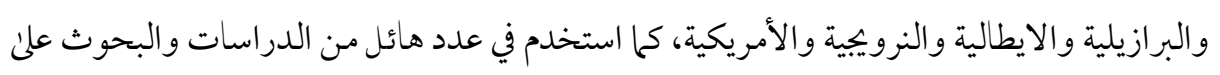
مستوي العالم. ولقد استخدم المقياس في العديد من الدراسات العربية والأجنبية بصورتيه المطولة والمختصرة. وتوصلت (ابر اهيم الشيخ، r ا • r) لمعاملات ثبات للمقياس بطريقة الفا كرونباك حيث كانت قيمته 9 و 9 , · كما توصلت لمعاملات ارتباط بين الأبعاد الأربعة للمقياس في نسخته الاصلية والعربية لقيم

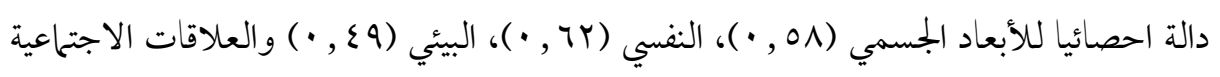

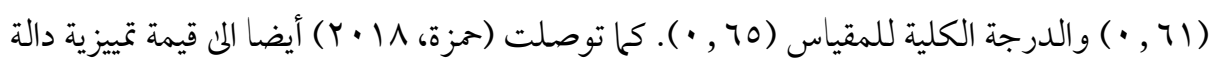
إحصائيا بين المرتفعين والمنخفضين في جودة الحياة، كما توصلت لقيم اتساق داخلي لأبعاد المقياس

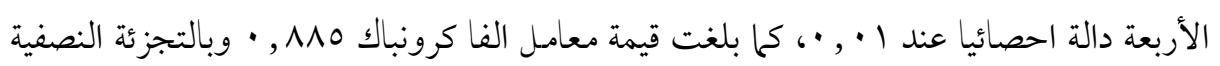

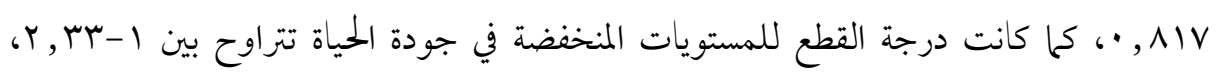


Prof. Dr. Ali Mahmud Shoeib

Volume (4) No. (2) 2021

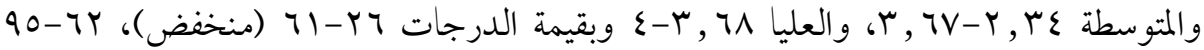

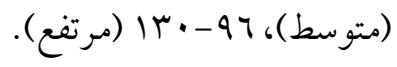

مؤشرات الثبات والصدق لأدوات الدراسة

يوضح الجدول رقم (1) بيان بنتائج الفا كرونباك والتجزئة النصفية لأدوات الدراسة جدول (1) نتائج الفاكرونباك والتجزئة النصفية لأدوات الدراسة: القلق العام GAD-7، الحساسية الانفعالية، الاكتئب لهاملتون، الاكتئاب PHQ-9

\begin{tabular}{|c|c|c|c|c|c|}
\hline جودة الحياة & الاكتئاب(PHQ-9) & الاكتئاب (هاملتون) & الحساسية الانفعالية & القلق العام & \\
\hline$\cdot, \wedge \varepsilon ৭$ & $\cdot, \wedge \vee 1$ & $\cdot, \wedge \wedge \wedge$ & $\cdot, \mathrm{V} \vee \mathrm{T}$ & $\cdot, \wedge r v$ & الفا كرونباك \\
\hline$\cdot, \vee>77$ & $\cdot, \Lambda \backslash \vee$ & $\cdot$, VAr & $\cdot, \vee १ ৭$ & $\cdot, \wedge \mu \cdot$ & التجزئة النصفية \\
\hline
\end{tabular}

وتشير نتائج الثبات الموضحة بالجدول لارتفاعها مما يطمئن لاستخدامها في القياس. ويوضح الجدول رقم (Y) بيان بنتائج الاتساق الداخلي لأدوات الدراسة القلق العام GAD-7، الحساسية

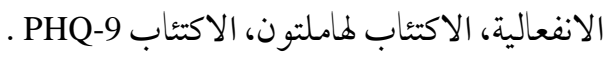
جدول (Y) نتائج الاتساق الداخلي لأدوات الدراسة: القلق العام GAD-7، الحساسية الانفعالية، الاكتئاب هلملتون، الاكتئاب PHQ-9

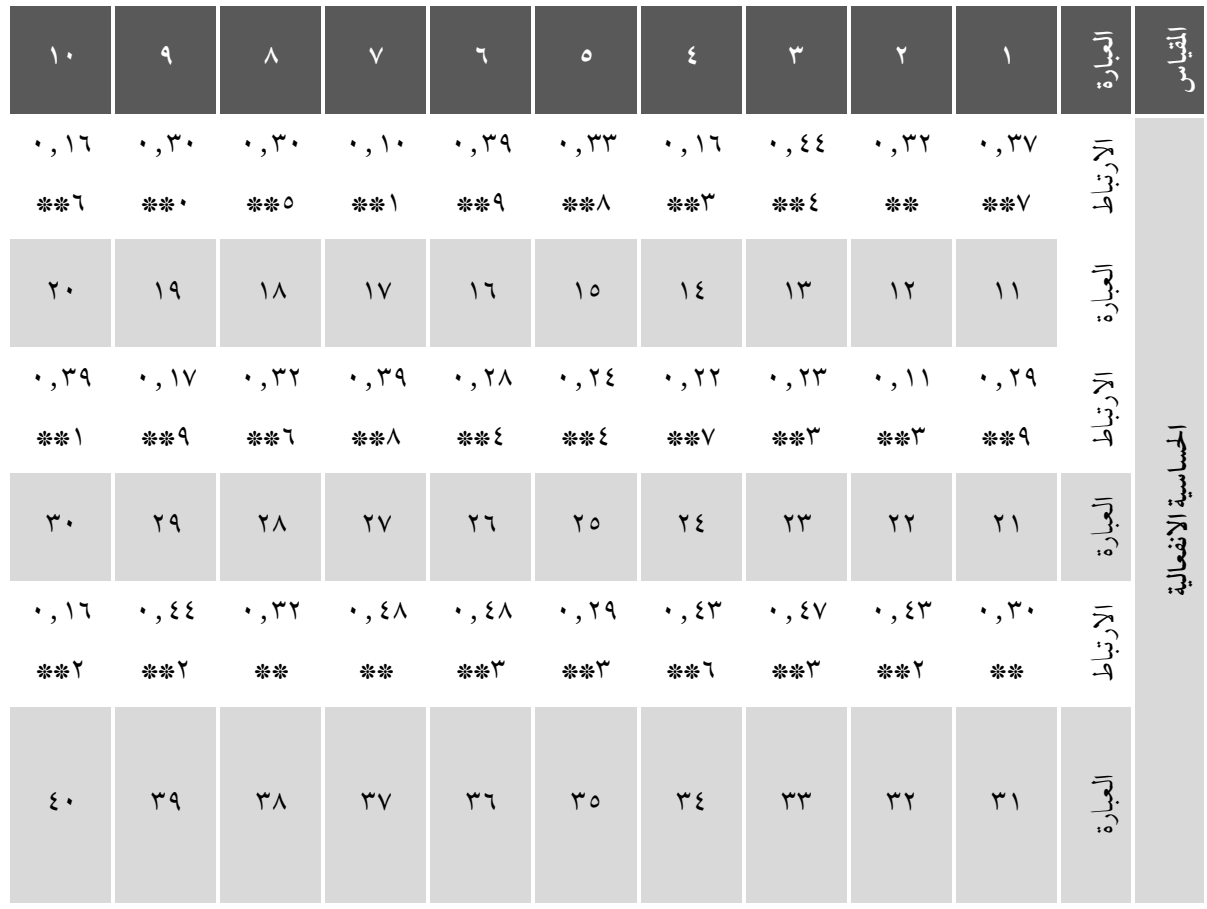

http://dx.doi.org/10.29009/ijres.4.2.2 


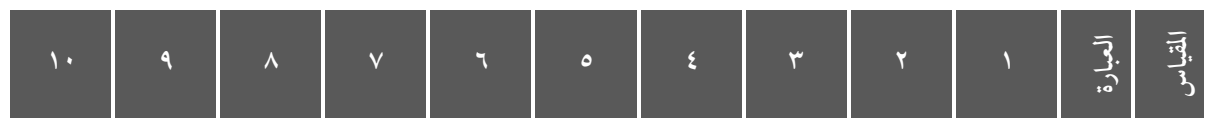

\begin{tabular}{|c|c|c|c|c|c|c|c|c|c|}
\hline$\cdot, \varepsilon V$ & $\cdot, r q$ & $\cdot, r r$ & $\cdot \mu_{1}$ & $\cdot, r \wedge$ & $\cdot, r y$ & $\cdot$, ro & $\cdot, \cdots$ & $\cdot, r \varepsilon$ & $\cdot, r r$ \\
\hline$* * * V$ & ***7 & *** & *** & $* * V$ & ***r & **1 & 0 & **7 & *** \\
\hline
\end{tabular}
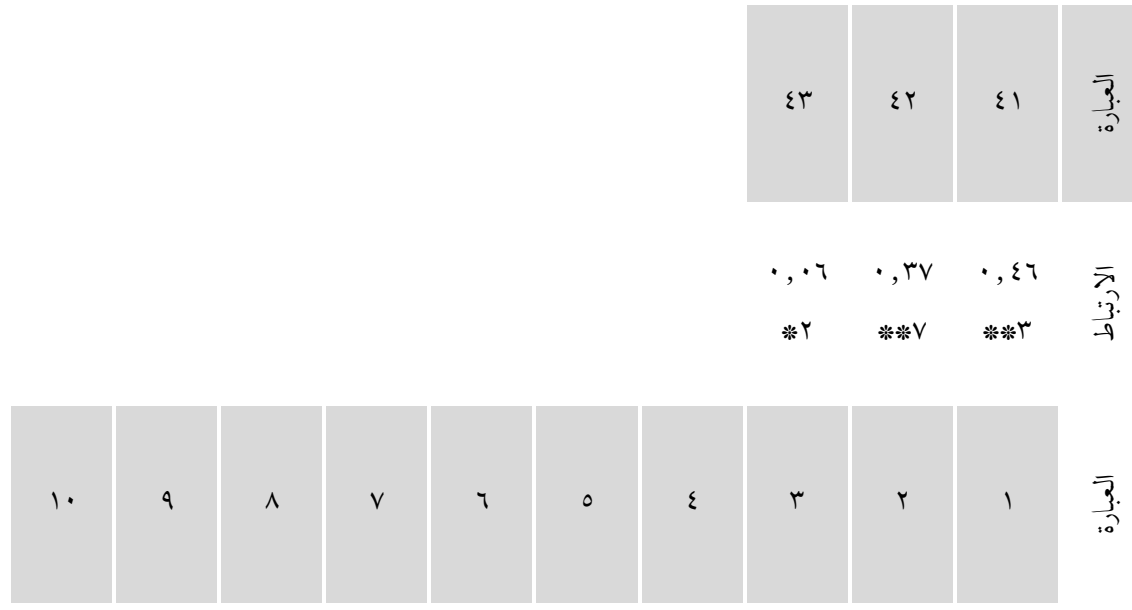

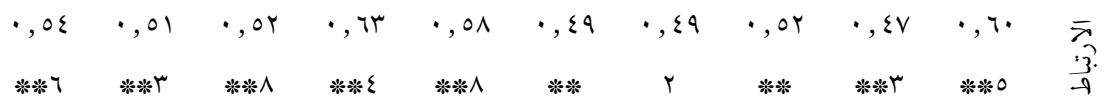
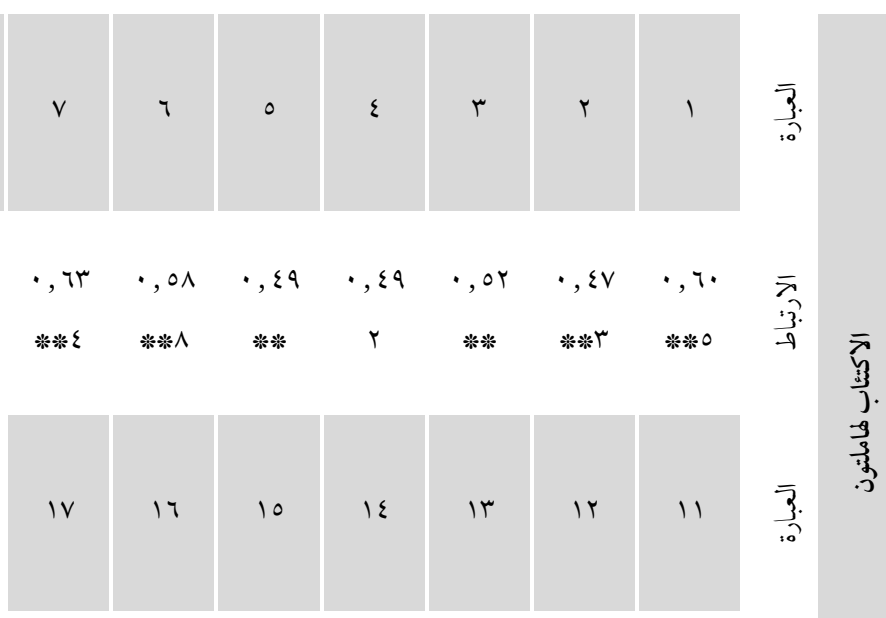

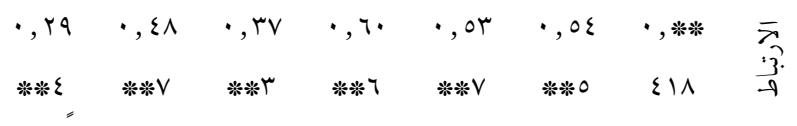

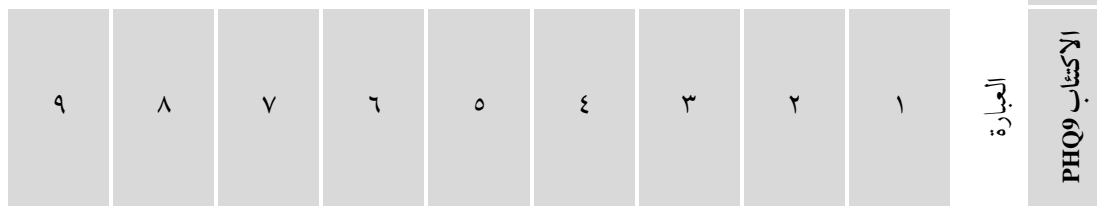

http://dx.doi.org/10.29009/ijres.4.2.2 

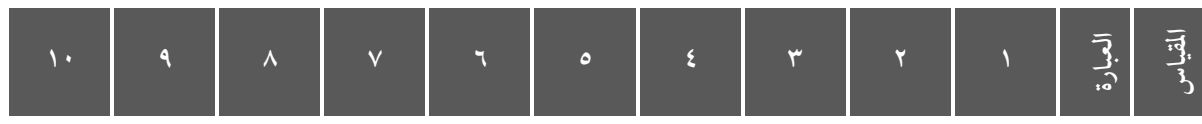

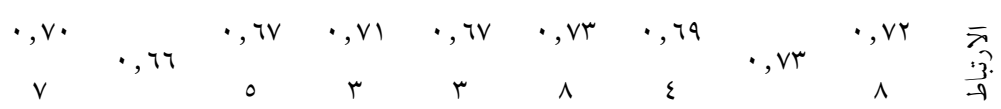
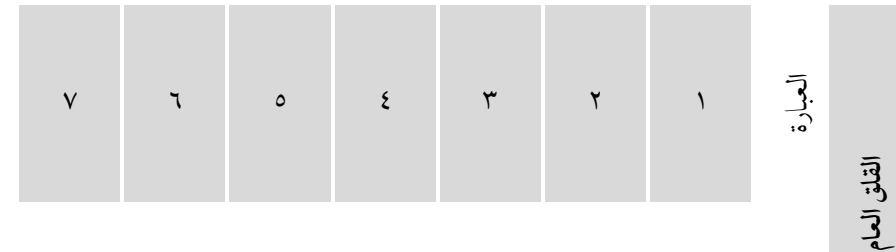

$$
\begin{aligned}
& * \cdot, \vee \quad \cdot, v r \quad \cdot, v 1 \quad \cdot, 74 \quad \cdot, v r \quad \cdot, v 1 \quad \cdot, v \cdot \quad \bar{r}
\end{aligned}
$$

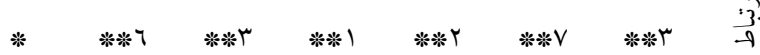

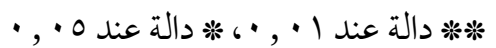

ولقد تم التحقق من صدق مقياس اضطر اب القلق العام GAD-7 باستخدام التحليل العاملي

الاستكشافي بطريقة principal components ومؤشر Eigen مقداره (1) وتشبع •ع , • ومعامل تحديد 0.194 حيث يتكون المقياس من V عبار ات تم تطبيقه علن عينة قو امها س 1 • ا طالب وطالبة حيث اسفرت نتائجه بعد التدوير بالفار يماكس علن عامل واحد فقط فسر بrV , إه من التباين ويتكون من T عبار ات كما هو موضح بالجدول (r) . و اشارت قيم KMO ان قيمة كاي تربيع دالة احصائيا.

\begin{tabular}{|c|c|c|c|c|}
\hline 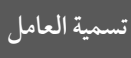 & التشبع & 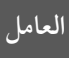 & 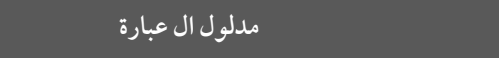 & 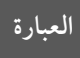 \\
\hline \multirow{6}{*}{ 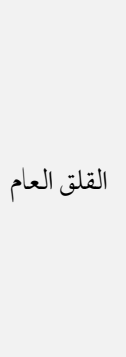 } & .750 & \multirow{6}{*}{1} & قلق أكثر من اللازم حول موضوعات نختلفة & GAD3 \\
\hline & .736 & & شديد التوتر بها جعلني غير مستقر في جلسة محدد & GAD5 \\
\hline & .716 & & الشعور بالعصبية، والزهق، والوصول المي حافة الانهيار & GAD1 \\
\hline & .712 & & غير متحكم في ضبط انفعالاتي وقلقي & GAD2 \\
\hline & .707 & & مذعور لدرجة احساسي ان مصيبة سوف تحدث & GAD7 \\
\hline & .693 & & افتقد القدرة علئ الشعور بالر احة والهدوء او الاستقرار & GAD4 \\
\hline
\end{tabular}

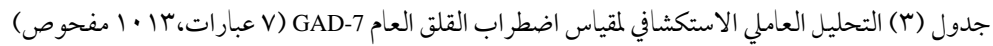

http://dx.doi.org/10.29009/ijres.4.2.2 
ولقد تم التحقق من صدق أداة الحساسية الانفعالية باستخدام التحليل العاملي الاستكشافي، حيث يتكون المقياس من rع عبارة تم تطبيقه على عينة قوامها س | • ا طالب وطالبة، ثم جدراء التحليل العاملي التوكيدي

- متائج التحليل العاملي الاستكشافي: Explanatory Factor Analysis (EFA) تمت عملية التحليل العامل الاستكشافي بطريقة principal components باستخدام برنامسج

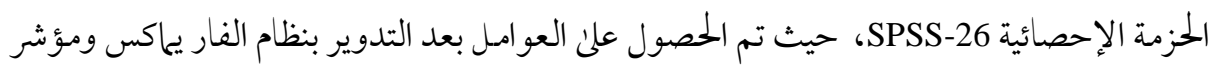

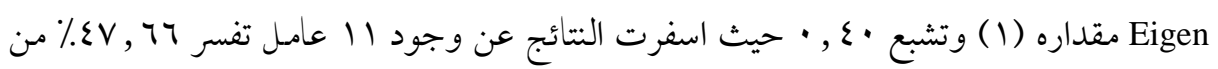

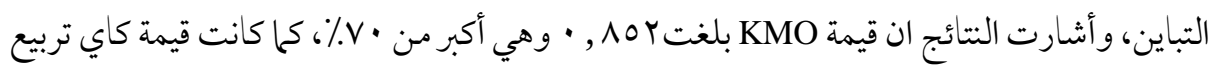

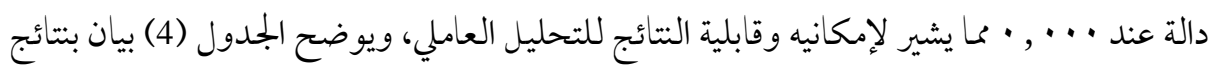
التحليل العاملي في صورته النهائية بعد التدوير بنظام الفار يماكس ودرجة تشبع العبارات به مرتبة

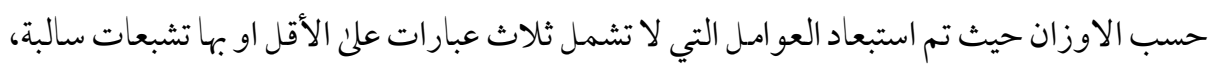
فاقتصرت العوامل على ستة عو امل فقط.

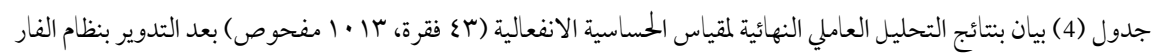
يماكس مرتبة حسب الأوزان

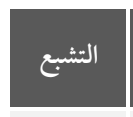

.615

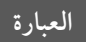

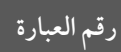

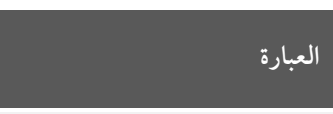

$$
\text { دائم اللوم لذاتي }
$$$$
\text { يخذلني أصدقائي }
$$$$
\text { دائما أتوقع أسوأ السيناريوهات لأي عمل أقوم به }
$$$$
\text { أحيانا ينتابني الإحساس ان لا أحد يهتم بي }
$$$$
\text { لدي إحساس انني سببت مضايقات كثيرة للأخرين }
$$ 
Prof. Dr. Ali Mahmud Shoeib

Volume (4) No. (2) 2021

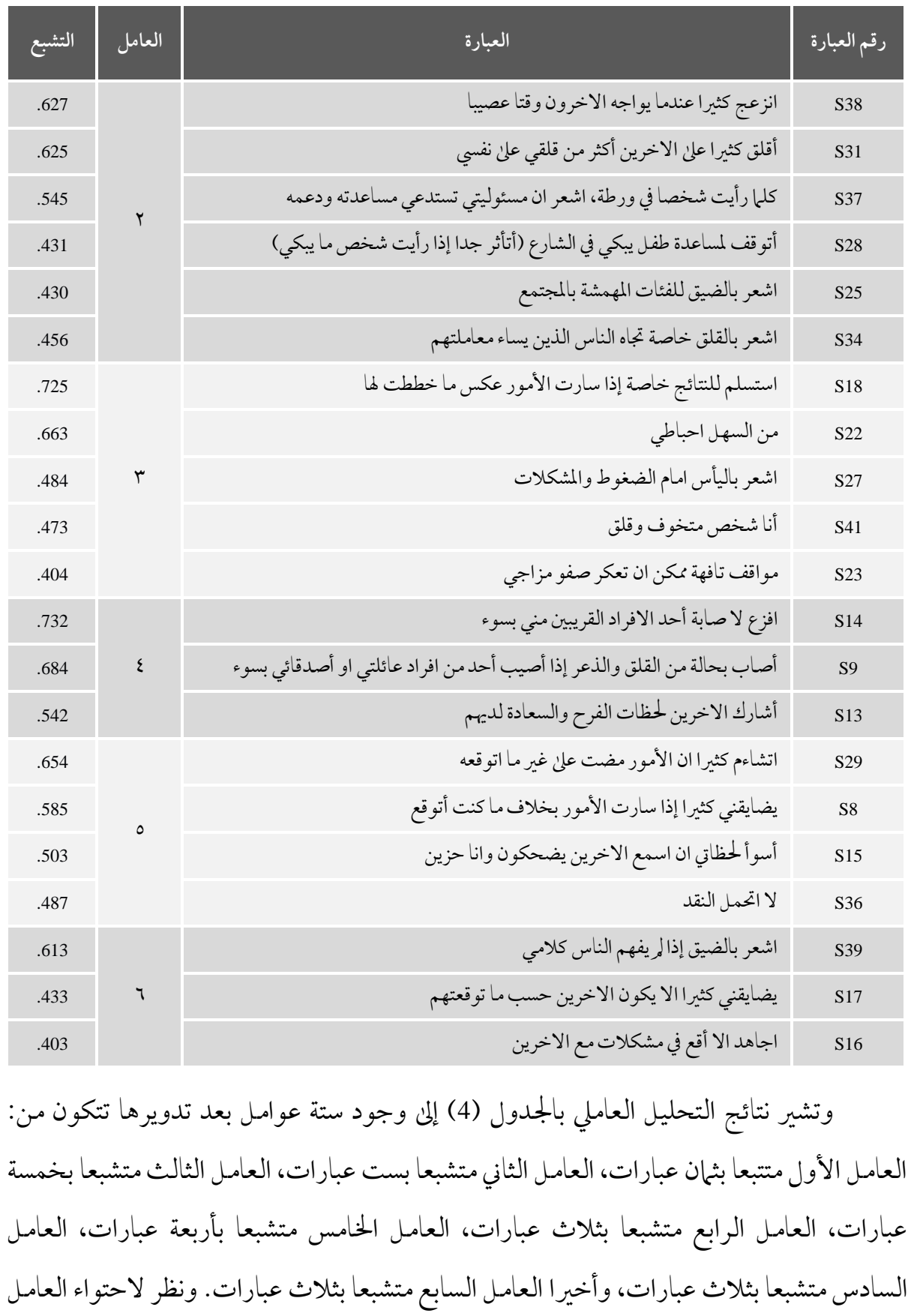

\section{http://dx.doi.org/10.29009/ijres.4.2.2}


السادس علن عبارة ذات تشبع سالب فبحذفها سيتم حذف البعد كاملا حيث سيتبقى فيه عبارتين فقط، ليصبح المقياس بعد التدوير في ثمان وعشرون عبارة موزعة علن 7 أبعاد. وتم عرض الابعاد علن محكمين في التخصص (^) وتم الاتفاق علئ تسمية الابعاد كالتالي: لوم الذات، الحساسية الانفعالية الإيجابية، ضغوط الحساسية الانفعالية، التعاطف، الحساسية الانفعالية السالبة، حساسية القلق.

- متائج التحليل العاملي التوكيدي:Confirmatory Factor Analysis (CFA) -

وفي ضوء نتائج التحليل العاملي الاستكشافي والتصور النظري للحساسية الانفعالية، فقد أظهر

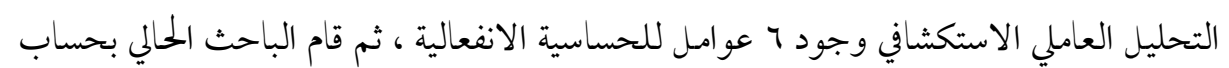
الصدق البنائي للمهام بالتحليل العاملي التوكيدي باستخدام برنامج AMOS . بهدف قياس جودة

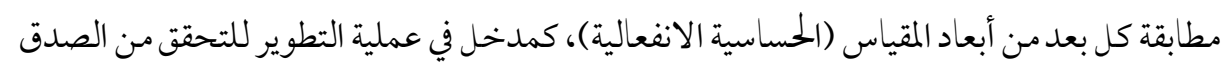
البنائي للمقاييس المختلفة التي تم بناؤها في ضوء الدراسات السابقة، والتوصل إلى البنود الفرعية الأكثر أهمية في كل بعد علن حده One-dimensionality ، وأشار (2004) Schumacher, \& Lomax, إلن مؤشرات المطابقة التالية للنموذج البنائي الافتراضي: ا ـ المؤشر المعياري:Normed Chi-Square

وهو عبارة عن النسبة بين قيمة إلى درجات الحرية، علماً بأن حد القبول لهذا المؤشر أقل من القيمة (0) ليدل علن إمكانية مطابقة النموذج الفعلي للنموذج، أما إذا كانت قيمة ذلك المؤشر أقل من القيمة (r) دل ذلك علن أن النموذج المقدر مطابق تماماً للبيانات المشاهدة المقدر (Carmines \& Mclver,1981). ومن الممكن استخدام مستوئ المعنوية المصاحب للاختبار كمقياس لجمودة التوفيق علن أساس ما إذا كان مستوئ المعنوية أكبر من (0 • , • ) ليدل ذلك على قبول فرض العدم القائل بمطابقة النموذج الفعلي

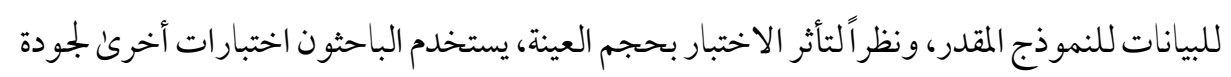

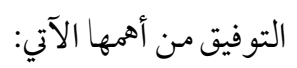


Goodness of Fit Index (GFI): مؤشر جودة المطابقة يوضح الدرجة الكلية لتوافق مربع البو اقي المحسوب من البيانات المقدرة من خلال النموذج إلى مربع البو اقي المحسوب من البيانات الفعلية، دون حاجته إلى التعديل بدرجات الحرية، هذا وتتراوح قيمته بين (•، (1)، وكلما اقتربت قيمته من الواحد الصحيح كلما دل ذلك على جودة مطابقة النموذج المقدر لبيانات عينة البحث (Tanaka, \& Huba. 1985)

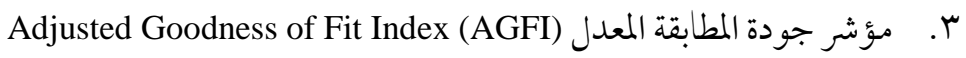
يهتم هذا المؤشر بتعديل مؤشر جودة المطابقة (GFI) بدرجات الحرية adjusted goodness of fit) (index) هذا وتتراوح قيمته بين (•، ( )، وكلم) اقتربت قيمته من الواحد الصحيح كلم) دل ذلك علن جودة مطابقة النموذج المقدر لبيانات عينة البحث (Tanaka \& Huba, 1985).

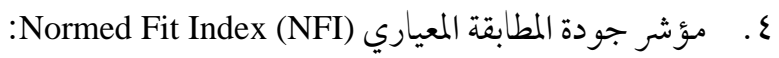
تتراوح قيمته بين (•، ())، وكلم) اقتربت قيمته من الواحد الصحيح كلم) دل ذلك على جودة مطابقة النموذج المقدر لبيانات عينة البحث (Bentler, 1980). 0. مؤشر جودة المطابقة المقارن Comparative Fit Index (CFI) Null Model Model Bassline كنموذج بمقارنة النموذج المقدر إلى النموذج الأساسي وتتراوح قيمته بين (•، ( )، وكلما اقتربت قيمته من الو احد الصحيح كلما دل ذلك على جودة مطابقة النموذج المقدر لبيانات عينة البحث.

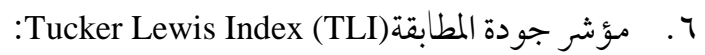
تقع قيم مؤشر (TLI) بين (•، ( )، وكلما اقتربت قيمته من الو احد الصحيح كلما دل ذلك علن جودة مطابقة النموذج المقدر لبيانات عينة البحث (Bentler, 1980). Incremental Fit Index (IFI): مؤشر جودة المطابقة المتز ايد تتراوح قيمته بين (•، ( )، وكلم) اقتربت قيمته من الواحد الصحيح كلما دل ذلك علن جودة مطابقة النموذج المقدر لبيانات عينة البحث (Bollen, 1989). 
^. الجذر التربيعي لمتوسط مربعات البواقي:Root Mean Square Residual (RMR) لا يو جد حدمعين للقبول، ولكن كلما انخفضت قيمة (RMR) كلما دل ذلك علن جودة مطابقة النموذج المقدر لبيانات عينة البحث(Hair, Black, Babin, Anderson \& Tatham, ,2006) 9 هoot Mean Square Error of الجذر التربيعي لمتوسط مربعات خطأ التقدير Approximation (RMSEA):

يقيس جودة مطابقة النموذج لمجتمع البحث، ومن ثم فإنه يأخذ في حسابه محاولة تصحيح كل من: تعقيد النموذج وحجم العينة، وحد القبول لهذا المؤشر أقل من (^• , •)، كلما انخفضت قيمة

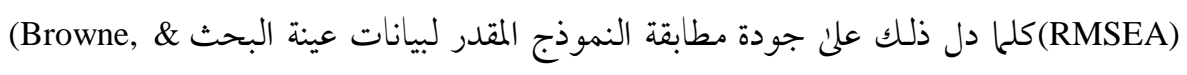
Cudeck,1993) • م ا معلمات الانحدار المعيارية:Standardized Loading Estimates Factor Loading تسمى معاملات الانحدار المعيارية المقدرة بمعاملات التشبع علن العوامل الكامنة و كلما زادت قيم تشبعات المتغيرات على العوامل الكامنة كلما دل ذلك على صدق الاتساق الداخلي لمقياس البحث. ويجب ألا تقل قيمة المعلمات الانحدارية المعيارية عن ( • , • )، والقيمة المثلي هي : (0.70).

11 ـ ـ متوسط نسبة التباين المُفسر:Average Variance Extracted (AVE) يُقاس متوسط نسبة التباين المفسر بمجموع مربعات تشبعات العامل -مربع معاملات الارتباط المتعدد - Squared Multiple Correlations مقسو ماً علن عدد المتغيرات بالنموذج محل القياس. وقد استخدم الباحث برنامج Analysis of Moment Structures (AMOS) لتقدير النموذج المقترح وإجراء اختبارات جودة المطابقة بهدف تخفيض أو تقليص عدد المؤشرات المعبرة عن المتغيرات الكامنة المتعلقة بالحساسية الانفعالية وذلك لكي يتمتع المقياس بجودة عالية. ويمكن تلخيص هذه المؤشرات كما هو مبين بالجدول (ع ). كما يوضح الشكل رقم (1) نموذج التحليل العاملي التو كيدي المقترح لمقياس AMOS. الحساسية الانفعالية باستخدام برنامج 
Prof. Dr. Ali Mahmud Shoeib

Volume (4) No. (2) 2021

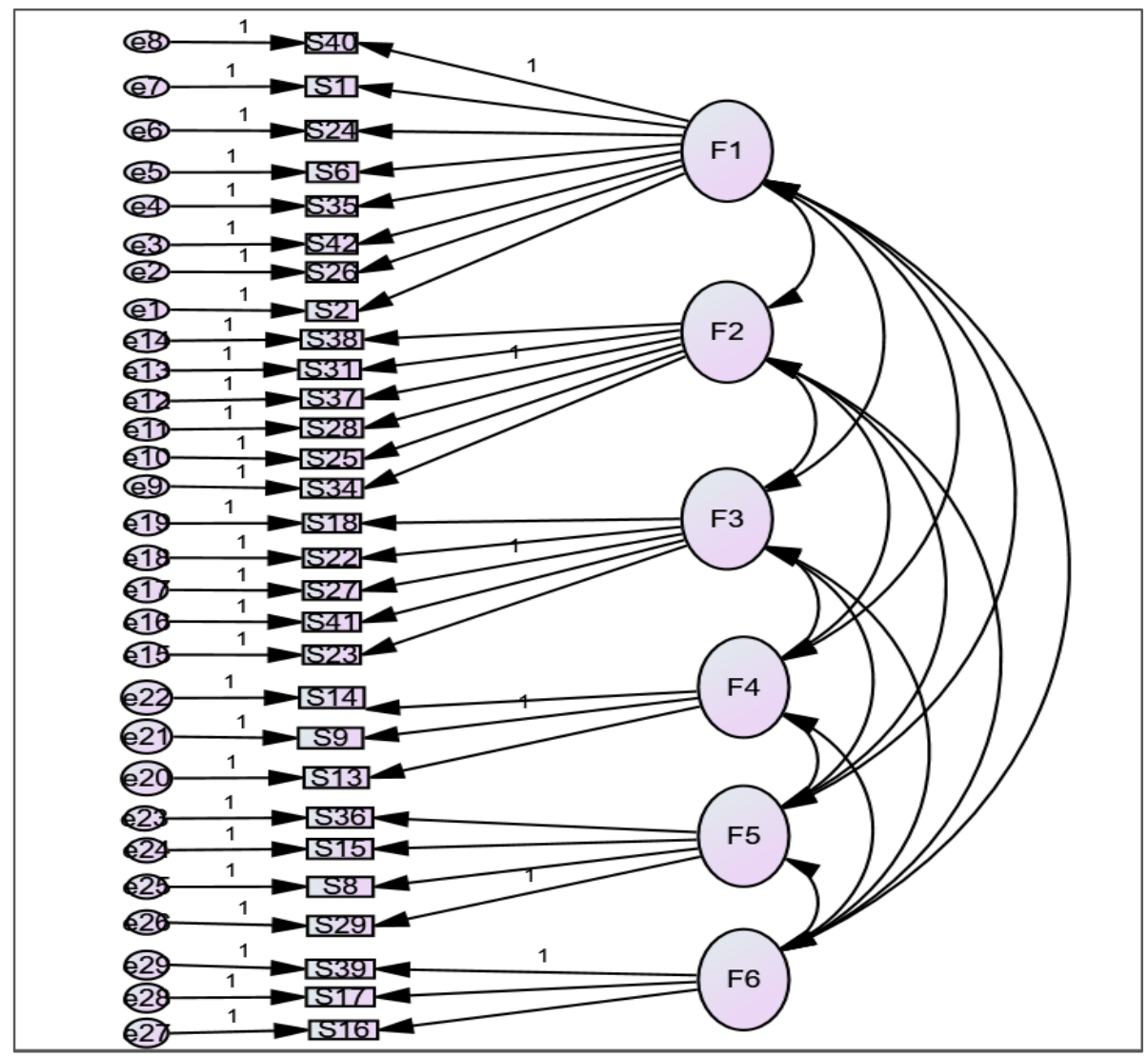

شكل رقم (1) نموذج التحليل العاملي التوكيدي المقترح لمقياس الحساسية الانفعالية باستخدام برنامج(AMOS)

جدول (5) مؤشرات حسن المطابقة للنموذج المقترح للعوامل البنائية في مقياس الحساسية الانفعالية

\begin{tabular}{|c|c|c|c|c|}
\hline قيمة المؤشر & المدى المثالي للمؤشر & 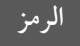 & \multicolumn{2}{|c|}{ مؤشرات حسن المطابقة } \\
\hline 1,910 & (• ( إلى 0) & $\mathrm{x} 2 / \mathrm{df}$ & Chi-Square /df & $\begin{array}{l}\text { النسبة بين مربع كاي } \\
\text { ودرجات الحرية df }\end{array}$ \\
\hline$\cdot, 90 \mathrm{r}$ & (• ( إلى 1) & GFI & Goodness of Fit Index & مؤشر حسن المطابقة \\
\hline$\cdot, 9 \varepsilon r$ & (• • إلى 1) & AGFI & $\begin{array}{l}\text { Adjusted Goodness of Fit } \\
\text { Index }\end{array}$ & مؤشر حسن المطابقة المصحح \\
\hline י & (• إلى 1) & NFI & Normed Fit Index & مؤشر المطابقة المعياري \\
\hline$\cdot, 9 \cdot 9$ & (• ( إلى 1) & CFI & Comparative Fit Index & مؤشر المطابقة المقارن \\
\hline
\end{tabular}

http://dx.doi.org/10.29009/ijres.4.2.2 


\begin{tabular}{|c|c|c|c|c|}
\hline قيمة المؤشر & المدى المثالي للمؤشر & 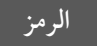 & \multicolumn{2}{|c|}{ مؤشرات حسن المطابقة } \\
\hline$\cdot, 91$ & 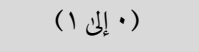 & IFI & Incremental Fit Index & مؤشر المطابقة التزايدي \\
\hline$\cdot, \wedge ৭ \vee$ & 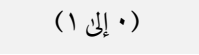 & TLI & Tucker-Lewis Index & مؤشر توكر لويس \\
\hline$\cdot, \cdot r$ & (• ( إلى 1) & RMSEA & $\begin{array}{l}\text { Root Mean Square Error of } \\
\text { Approximation }\end{array}$ & مؤشر جذر متوسط مربع \\
\hline
\end{tabular}

ويتضح من جدول (5) أن النموذج المفترض للحساسية الانفعالية يطابق تماما بيانات عينة

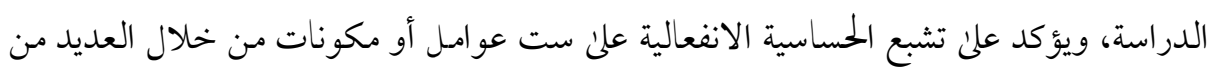
المؤشرات الدالة على جودة هذه المطابقة والتي يتم قبول النموذج المفترض للبيانات أو رفضه في ضوئها والتي تعرف بمؤشرات جودة المطابقة، حيث وقعت مؤشرات جودة المطابقة جميعها في المدى المثلي لها، حيث كانت النسبة بين كاي تربيع ودرجات الحرية وقعت في المدىن المثالي وهي (910 و ـ 1 ) فإذا كانت هذه القيمة أقل من ه تدل على قبول النموذج، ولكن إذا كانت أقل من ب تدل علن أن النموذج المقترح

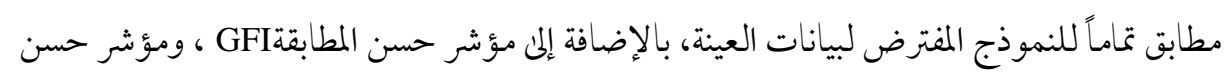

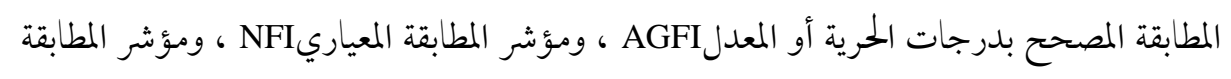
المقارنCFI ، مؤشر المطابقة التزايديIFI مؤشر توكر لويس TLI وجميعها قيم مرتفعة تصل إلى حد

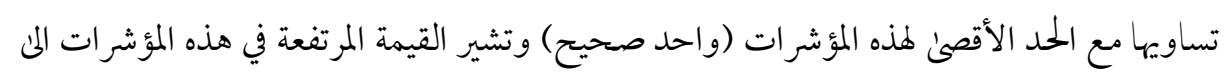

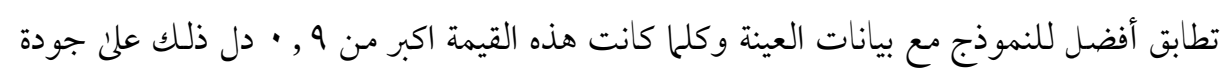

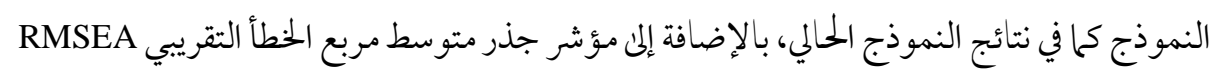
وهو من أهم مؤشرات جودة المطابقة في التحليل العاملي التوكيدي فإذا ساوت قيمته ه • , • فأقل دل ذلك علن أن النموذج يطابق تمامـا البيانات، وإذا كانت محصورة بين 0 • , • ، • • , • فإن النموذج يطابق بدرجة كبيرة بيانات العينة، أما إذا زادت قيمته عن ^ • , · فيتم رفض النموذج، وبلغت قيمته في البحث

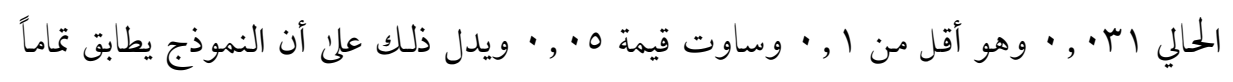

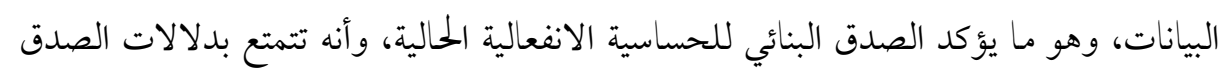


Prof. Dr. Ali Mahmud Shoeib

Volume (4) No. (2) 2021

العاملي البنائي علن البيئة المصرية. ويوضح الشكل (r) النموذج المفترض للحساسية الانفعالي

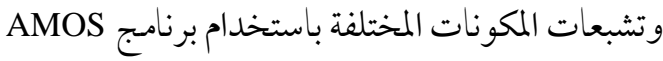

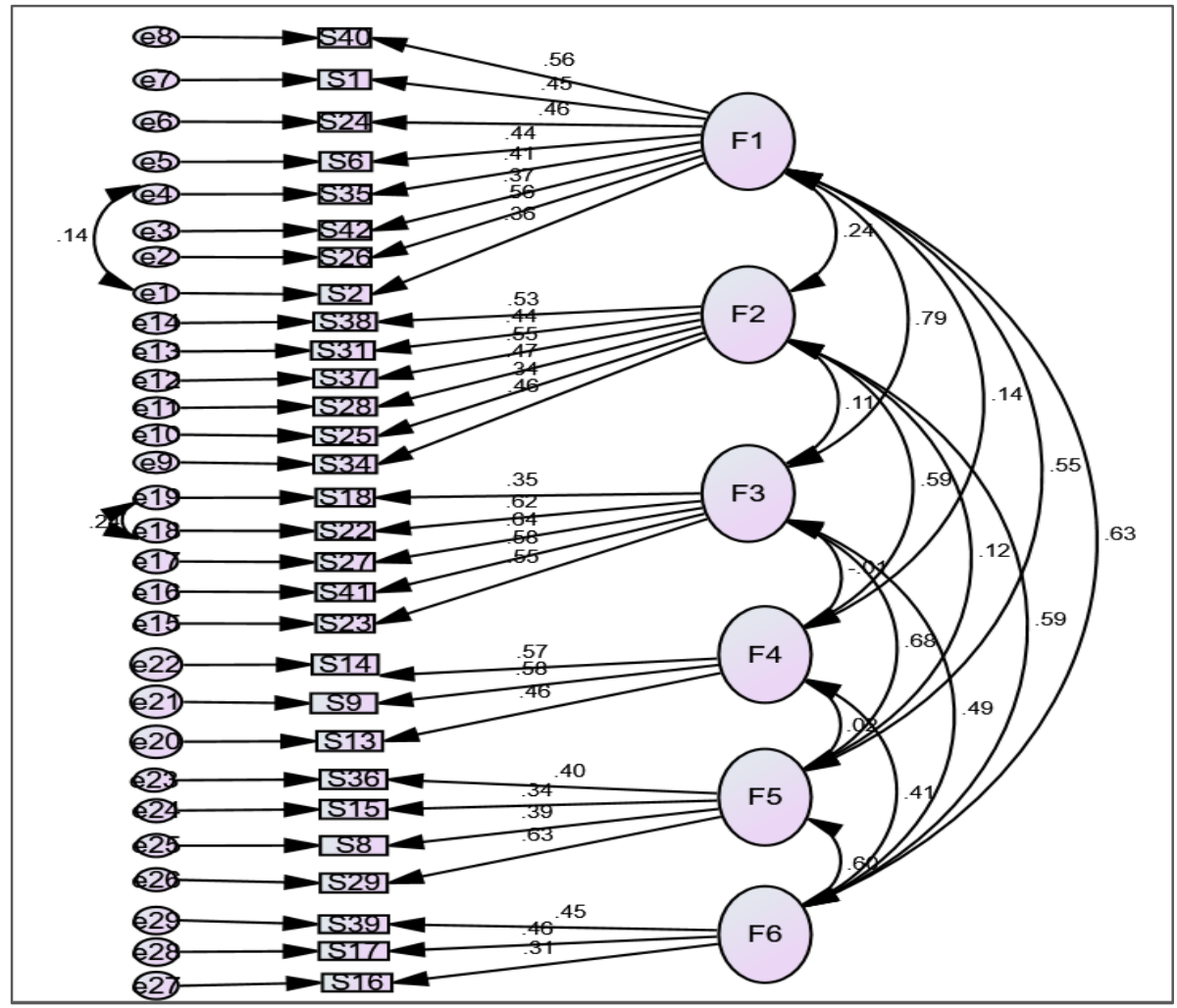

شكل (r) النموذج سداسي عوامل الحساسية الانفعالية لدن عينة البحث

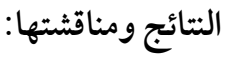
الفرض الأول: يتصف طلاب الجامعة بالحساسية الانفعالية والقلق والاكتئاب. ولقد تم اختبار صحة : الفرض احصائيا بالمتو سط الوزني لكل عبارة من عبارات المقياس والدرجة الكلية. ويوضح الجدول (6) بيان بنتائج اختبار الفرض احصئيائ.

http://dx.doi.org/10.29009/ijres.4.2.2 
جدول (6) مدئ شيوع كل من القلق العام والاكتئاب والحساسية الانفعالية لدئ طلاب الجامعة (ن با • ())

\begin{tabular}{|c|c|c|c|c|c|c|c|c|c|c|c|}
\hline 1. & 9 & $\wedge$ & V & 7 & 0 & $\varepsilon$ & $r$ & r & 1 & العبارة & المتغير \\
\hline $1, \wedge r$ & 1,91 & $1, \times 7$ & 1, vo & 1, vo & $1,\{7$ & 1,10 & 1,71 & 1, ro & ז', & متوسط & \multirow{19}{*}{ 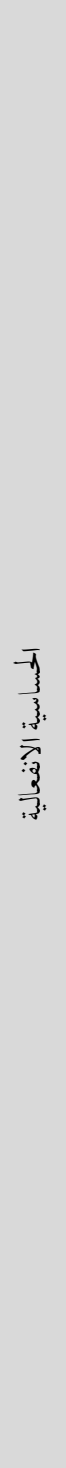 } \\
\hline$\cdot, r \varepsilon$ & $\cdot, Y^{\prime}$ & $\cdot$, • $\{r$ & 1.7532 & 1.7483 & 1.4630 & 1.8509 & 1.6061 & 1.3485 & 1.6219 & انحراف & \\
\hline ينطبق & ينطبق & ينطبق & ينطبق & ينطبق & ע & ينطبق & ينطبق & ע & ينطبق & الشيوع & \\
\hline$r$. & 19 & 11 & IV & 17 & 10 & $1 \varepsilon$ & ir & Ir & 11 & العبارة & \\
\hline $1, V Y$ & 1,11 & $1, \varepsilon 0$ & $1, \mathrm{vV}$ & $1, \wedge 9$ & $1, r r$ & $1,9 Y$ & $1, Q Y$ & $1, r^{\prime}$ & Y & متوسط & \\
\hline$\cdot$, , & $\cdot, \varepsilon \cdot$ & $\cdot, 0$. & $\cdot, \varepsilon r$ & r & $\cdot, \varepsilon V$ & $\cdot, r \cdot$ & $\cdot, r V$ & $\cdot, \varepsilon \varepsilon$ & $\cdot, \varepsilon 9$ & انحر اف & \\
\hline ينطبق & ينطبق & ע & ينطبق & ينطبق & لا & ينطبق & ينطبق & ע & ينطبق & الشيوع & \\
\hline$r$. & Yq & YA & rV & T & ro & $Y \varepsilon$ & Yr & YY & YI & العبارة & \\
\hline 1,10 & $1,0$. & $1, \wedge \wedge$ & $1,0 \xi$ & $1,7 V$ & $1, v 7$ & $1, \wedge 9$ & $1, r r$ & $1,9 r$ & $1,9 r$ & متوسط & \\
\hline$\cdot$, ro & $\cdot, 0$. & $\cdot, r r$ & $\cdot, 0$. & $\cdot, \varepsilon V$ & · & r & $\cdot,\{V$ & $\cdot, r \cdot$ & $\cdot, r V$ & انحراف & \\
\hline ينطبق & ينطبق & ينطبق & ينطبق & ينطبق & ينطبق & ينطبق & ينطبق & ע & ينطبق & الشيوع & \\
\hline$\varepsilon$. & rq & rı & rv & rq & ro & $r \varepsilon$ & זיץ & rY & ri & العبارة & \\
\hline $1, T Y$ & $1, \mathrm{~V} \wedge$ & $1, \wedge r$ & $1,9$. & $1, \varepsilon 1$ & $1, \varepsilon \wedge$ & $1, \wedge 1$ & $1, v \cdot$ & $1,\{\wedge$ & $1, v \varepsilon$ & متوسط & \\
\hline$\cdot, \varepsilon १$ & $\cdot,\{Y$ & $\cdot, r q$ & $\cdot, r$. & $\cdot, \varepsilon १$ & $\cdot, 0$. & $\cdot, r q$ & $\cdot, \varepsilon\rceil$ & $\cdot, 0$. & $\cdot, \varepsilon \varepsilon$ & انحراف & \\
\hline \multirow[t]{5}{*}{ ينطبق } & ينطبق & ينطبق & ينطبق & ע & ע & ينطبق & ينطبق & V & ينطبق & الشيوع & \\
\hline & & & & & & الكلية & $\varepsilon r$ & $\varepsilon Y$ & \&1 & العبارة & \\
\hline & & & & & & $1,7 V$ & זד, , & $1,0 r$ & 1,01 & متوسط & \\
\hline & & & & & & ع & $\cdot$, , & $\cdot, 0$. & $\cdot, \varepsilon १$ & انحراف & \\
\hline & & & & & & لا ينطبق & ينطبق & ينطبق & ينطبق & الشيوع & \\
\hline
\end{tabular}


Prof. Dr. Ali Mahmud Shoeib

Volume (4) No. (2) 2021

\begin{tabular}{|c|c|c|c|c|c|c|c|c|c|c|c|}
\hline 1. & 9 & $\wedge$ & V & 7 & 0 & $\varepsilon$ & $r$ & r & 1 & العبارة & المتغير \\
\hline $\begin{array}{l}\infty \\
\infty \\
0\end{array}$ & $\begin{array}{l}\infty \\
\infty \\
0\end{array}$ & $\begin{array}{l}n \\
\infty \\
0 \\
0\end{array}$ & s. & $\stackrel{n}{n}$ & $\begin{array}{l}\infty \\
\infty \\
0\end{array}$ & $N$ & ñ? & $\stackrel{\infty}{\stackrel{\sim}{\sim}}$ & $\stackrel{\text { f }}{\text { f }}$ & $\begin{array}{l}3 \\
3 \\
3\end{array}$ & \multirow{7}{*}{ 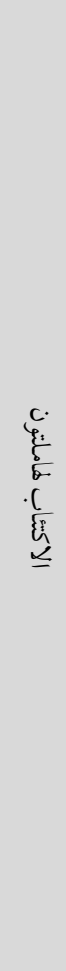 } \\
\hline$\stackrel{\sigma}{0}$ & $\begin{array}{l}n \\
\ddot{0}\end{array}$ & 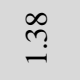 & $\stackrel{\Xi}{\Xi}$ & $\hat{n}$ & $\stackrel{\infty}{\infty}$ & $\stackrel{0}{=}$ & $\stackrel{\infty}{\rightleftarrows}$ & 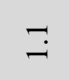 & ปี & $\frac{\overline{1}}{\overline{9}}$ & \\
\hline \multirow[t]{5}{*}{ के } & के & :3 & के & $\frac{y}{3}$ & के & : & :\$ & $\begin{array}{c}3 \\
3 \\
\text { जे }\end{array}$ & $\begin{array}{c}3 \\
3 \\
3 \\
\frac{1}{3}\end{array}$ & "3. & \\
\hline & & الكلية & IV & 17 & 10 & $1 \varepsilon$ & ir & Ir & 11 & $\overline{3}$ & \\
\hline & & $\cdot, \wedge \vee$ & 0.62 & 0.43 & 0.31 & 0.74 & 0.76 & 0.64 & 0.78 & $\begin{array}{l}3 \\
3 \\
3\end{array}$ & \\
\hline & & $\cdot,\{\rceil$ & 0.65 & 0.19 & 0.56 & 0.67 & 0.63 & 0.63 & 0.64 & $\frac{\overline{3}}{\overline{2}}$ & \\
\hline & & के & :\$ & 多 & : & :\$ & 3. & :3 & 3. & 馬: & \\
\hline الكلية & 9 & $\wedge$ & v & 7 & 0 & $\varepsilon$ & $r$ & $r$ & 1 & $\underset{3}{\overline{3}}$. & \\
\hline$\cdot, q \xi$ & זות, • & זוד, • & 1,19 & $\cdot, 70$ & $1, \cdot 0$ & $1, \cdot 9$ & $1, \cdot 1$ & $1,1 r$ & 1,11 & $\begin{array}{l}3 \\
3 \\
3\end{array}$ & \\
\hline$\cdot, 71$ & $\cdot, \wedge \mathrm{V}$ & $\cdot, \wedge 1$ & • , ar & $\cdot, \wedge 0$ & $\cdot, \wedge \wedge$ & $\cdot, \wedge \wedge$ & $\cdot, \wedge \wedge \varepsilon$ & $\cdot, \wedge \wedge$ & $\cdot, \wedge \cdot$ & $\frac{\overline{1}}{\overline{2}}$ & $\frac{\partial}{\mathbb{I}}$ \\
\hline :\$ & $\begin{array}{c}3 \\
3 \\
3 \\
\text { 3. }\end{array}$ & 各 & के & :3 & $\begin{array}{c}3 \\
\frac{3}{3} \\
\frac{3}{10}\end{array}$ & 3. & $\begin{array}{c}\text { के } \\
\frac{3}{3}\end{array}$ & के & के & 馬: & \\
\hline
\end{tabular}

http://dx.doi.org/10.29009/ijres.4.2.2 


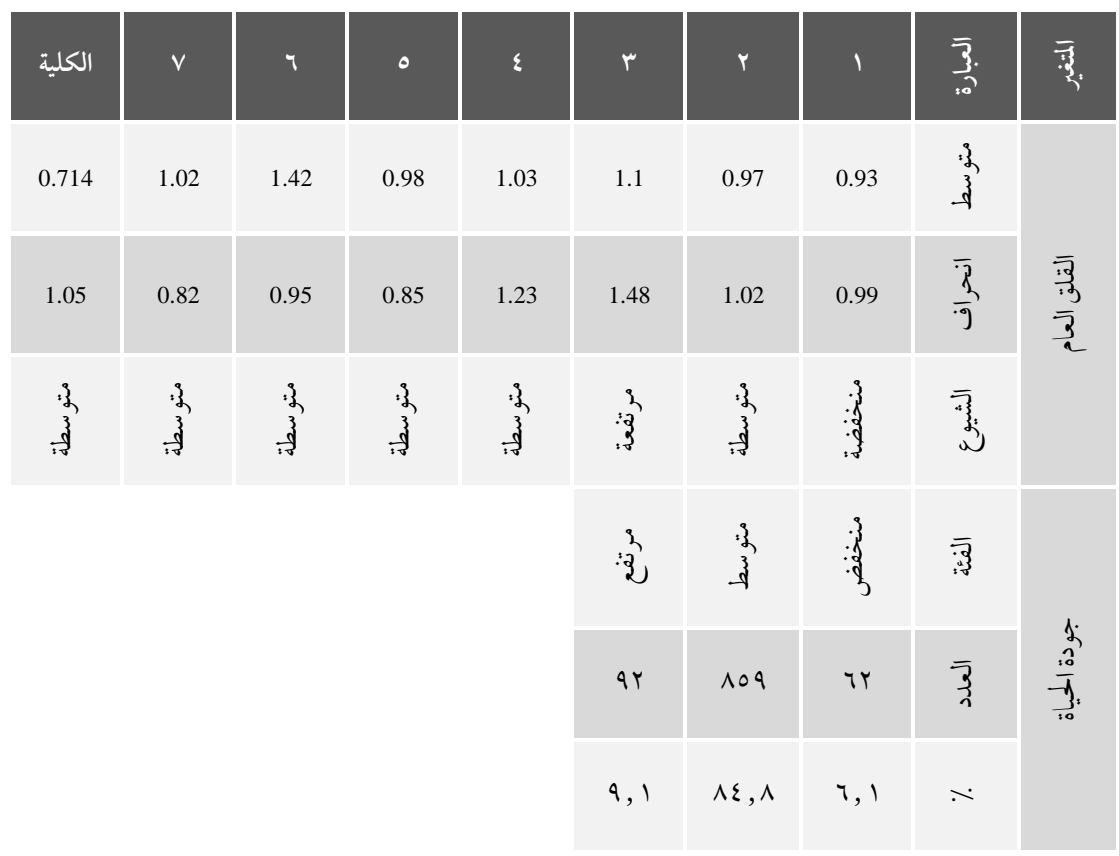

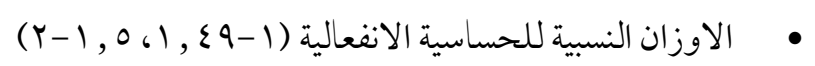

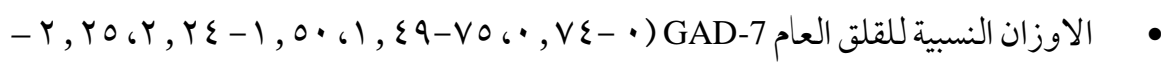

(r)

• الاوزان النسبية للاكتئاب لدئ طلاب الجامعة (• - \& V, • • •

$$
\left(r-r, r_{0}\right.
$$

وتوضح النتائج بالجدول (7) أن درجة شيوع القلق العام لدىن طلبة الجلمعة متوسطة، وأن درجة شيوع الحساسية الانفعالية لدىن طلاب الجامعة منخفضة، وأن درجة شيوع الاكتئاب بأسلوبي هاملتون وPHQ9 تراوحت بين المتوسطة والمنخفضة علن الترتيب، وان الغالبية العظمى يتمتعون

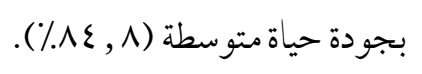


الفرض الثاني: توجد علاقة ارتباطية دالة احصائيا بين متغيرات الدراسة: الحساسية الانفعالية، القلق العام، الاكتئاب، وجودة الحياة لدىن طلاب الجامعة وتم اختبار صحة الفرض احصائيا باستخدام

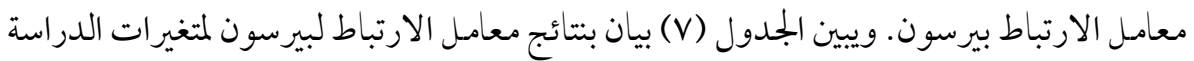
جدول (V) بيان بنتائج اختبار معامل ارتباط بيرسون لمتغيرات الدراسة: الحساسية الانفعالية، القلق العام، الاكتئاب (ن=س| • ( )

\begin{tabular}{|c|c|c|c|c|}
\hline \multirow[t]{4}{*}{ الاكتئاب(PHQ-9) } & الاكتئاب (هاملتون) & الحساسية الانفعالية & القلق العام & المتغيرات \\
\hline & & & $.444^{* *}$ & الحساسية الانفعالية \\
\hline & & $.393^{* *}$ & $.607^{* *}$ & الاكتئاب (هـاملتون) \\
\hline & $.768^{* *}$ & $.430^{* *}$ & $.626^{* *}$ & الاكتئاب(PHQ-9) \\
\hline - , $\{\varepsilon-* * *$ & -,$r \varepsilon r-* * * *$ & -, r $\{0-* * * *$ & • & جودة الحياة \\
\hline
\end{tabular}

وتشير النتائج الموضحة بالجدول (V) المي وجود علاقات ارتباطية ذات دلالة إحصائية بين متغيرات الدراسة مما يشير الما تأثر كل منها بالأخر. الفرض الثالث: لا توجد فروق ذات دلالة إحصائية بين متغيرات الدراسة: الحساسية الانفعالية، القلق العام، الاكتئاب، وجودة الحياة لدئ طلاب الجامعة بعامل الجنس. وتم اختبار صحة الفرض احصائيا باستخدام اختبار (ت) للفروق بين المتوسطات غير المرتبطة. ويوضح الجلدول (^) بيان بنتائج اختبار الفرض احصائيا

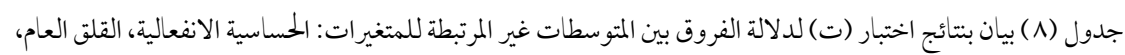

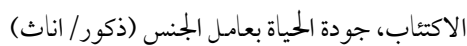

\begin{tabular}{|c|c|c|c|c|c|c|c|}
\hline الدلالة ل & قيمة ت & درجات الحرية & الانحراف المعياري & المتوسط & العدد & 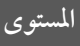 & المتغير \\
\hline \multirow{2}{*}{ دالة } & \multirow{2}{*}{$r, \| 1 V$} & \multirow{2}{*}{1.11} & $\varepsilon, \wedge \varepsilon \wedge$ & $7,1 \cdot \varepsilon 0$ & Ir & ذكور & \multirow{2}{*}{ القلق العام } \\
\hline & & & $\varepsilon, 977$ & $v, 0119$ & $\Lambda \vee q$ & اناث & \\
\hline \multirow{2}{*}{ دالة ل } & \multirow{2}{*}{$\varepsilon, \wedge 1 \gamma$} & \multirow{2}{*}{1.11} & $0, r \wedge$. & $79,8 \cdot 17$ & 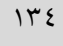 & ذكور & \multirow{2}{*}{ الحساسية الانفعالية } \\
\hline & & & ०, VAY 10 & VY, rorv & $\wedge \vee q$ & اناث & \\
\hline \multirow{2}{*}{ دالة ل } & \multirow{2}{*}{$r, \wedge \wedge 1$} & \multirow{2}{*}{1.11} & $1, .00 \mathrm{~V} 9$ & $\mid r, \varepsilon \varepsilon \vee \wedge$ & $1 \pi \varepsilon$ & ذكور & \multirow{2}{*}{ اكتئاب هاملتون } \\
\hline & & & $\vee, \wedge \varepsilon \cdot \varepsilon\urcorner$ & $10, r \vee 99$ & $\Lambda \vee q$ & اناث & \\
\hline
\end{tabular}




\begin{tabular}{|c|c|c|c|c|c|c|c|}
\hline 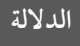 & قيمة ت & درجات الحرية & الانحر اف المعياري & المتوسط & العدد & المستوى & المتغير \\
\hline \multirow{2}{*}{ دالة } & \multirow{2}{*}{$r, Y \backslash q$} & \multirow{2}{*}{1.11} & $0,9 r \cdot 1 V$ & $\vee,\{\vee \vee \tau$ & 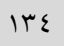 & ذكور & \multirow{2}{*}{ اكتئاب PHQ9 } \\
\hline & & & $0, r \vee \backslash \vee \varepsilon$ & $\wedge, 09 \wedge \varepsilon$ & AVq & اناث & \\
\hline \multirow{2}{*}{ غير دالة ل } & \multirow{2}{*}{$1, \varepsilon \cdot q$} & \multirow{2}{*}{$1 \cdot 11$} & Ir, rotv & $\vee q, \vee \leqslant \neg r$ & Ir & ذكور & \multirow{2}{*}{ جودة الحياة } \\
\hline & & & $11, r q \cdot v r$ & 11, rror & $\wedge \vee q$ & اناث & \\
\hline
\end{tabular}

وتشير النتائج الموجودة بالجدول (^) إلى وجود فروق في كل من القلق العام، والحساسية الانفعالية، الاكتئاب، وجودة الحياة حيث كانت قيمة ت دالة احصائيا عند مستويات أكبر من ا ل . , . لصالح الاناث، مما يشير الما رفض الفرض الثاني. الفرض الرابع: لا توجد فروق ذات دلالة إحصائية في كل من الحساسية الانفعالية وجودة الحياة بحسب مستويات القلق العام والاكتئاب. وتم اختبار صحة الفرض احصائيا باستخدام اختبار تحليل التباين الاحادي (ف) لدلالة الفروق بين المتوسطات، ويوضح الجدول (9) بيان بتنائج اختبار صحة الفرض احصائيا. جدول (9) نتائج تحليل التباين الأحادي للفروق بين المثوسطات في كل من الحساسية الانغعالية وجودة الحياة بمستويات القلق العام والاكئاب

\begin{tabular}{|c|c|c|c|c|c|c|c|}
\hline الدلالة & قيمة ف & متوسط المربعات & درجات & بموع المربعات & مصدر التباين & \multicolumn{2}{|c|}{ المتغير } \\
\hline دالة & \multirow{3}{*}{$\begin{array}{c}\Lambda 1, \varepsilon . \\
0\end{array}$} & $r r \varepsilon V, \varepsilon r\rceil$ & r & $\{79 \varepsilon, \wedge \vee 1$ & بين المجموعات & \multirow{3}{*}{ القلق } & \multirow{9}{*}{ الحساسية } \\
\hline & & 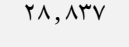 & $1 \cdot 1$. & rq1rE, 997 & داخل المل & & \\
\hline & & & $1 \cdot 1 r$ & 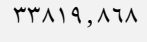 & & & \\
\hline دالة & \multirow{3}{*}{$\begin{array}{c}11 \cdot, 9 \\
91\end{array}$} & $r 791, \cdot r$ & r & orAr, $\cdot \varepsilon \cdot$ & داخل المج & \multirow{3}{*}{ هاملتون } & \\
\hline لصاكح & & $r \varepsilon, r \varepsilon 0$ & $9 \vee \varepsilon$ & rryו\&, 9Vr & بين المج & & \\
\hline المرتعين & & & $9 \vee 7$ & r^99V, $\cdot 11$ & الكلي & & \\
\hline \multirow{3}{*}{ لصالح المرتفعين } & \multirow{3}{*}{$\begin{array}{c}91,7 . \\
1\end{array}$} & ro97, \{99 & $r$ & $019 Y, 9 V \wedge$ & داخل المجموعات & \multirow{3}{*}{$\begin{array}{l}\text { اكتئاب } \\
\text { PHQ9 }\end{array}$} & \\
\hline & & $r \wedge, r \varepsilon r$ & 1.1. & 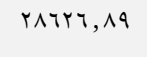 & بين المجموعات & & \\
\hline & & & $1.1 r$ & 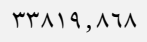 & الكلي & & \\
\hline
\end{tabular}

\section{http://dx.doi.org/10.29009/ijres.4.2.2}


Prof. Dr. Ali Mahmud Shoeib

Volume (4) No. (2) 2021

\begin{tabular}{|c|c|c|c|c|c|c|c|}
\hline الدلالة & قيمة ف & متوسط & درجات & بموع المربعات & مصدر التباين & \multicolumn{2}{|c|}{ المتغير } \\
\hline دالة & \multirow{3}{*}{$\varepsilon Y, Y \wedge Y$} & OrYA, Or & r & $1.70 \mathrm{~V}, .71$ & بين المجموعات & \multirow{3}{*}{ القلق } & \multirow{9}{*}{ جودة الحياة } \\
\hline لصاح & & $1 Y \tau, \cdot r \varepsilon$ & $1 \cdot 1$. & IYVYAE, +1 & داخل المجموعات & & \\
\hline المنحعصين & & & $1.1 r$ & |rV৭\&।, •VA & & & \\
\hline دالة & \multirow{3}{*}{$\varepsilon 1, \cdot r \varepsilon$} & $\varepsilon 97 r, 01$ & r & Q৭YV, $\cdot r$ & داخل المجموعات & \multirow{3}{*}{ هاملتئاب } & \\
\hline لصالح & & $1 \% \cdot, 97$ & $9 \vee \varepsilon$ & $\mid 1 V \wedge 10, \cdot 1 \varepsilon$ & بين المججموعات & & \\
\hline المنخفضين & & & $9 \vee 7$ & IrVVEr, $r_{0}$ & كليل - تلي & & \\
\hline دالة & \multirow{3}{*}{$9 \vee, \varepsilon \backslash \varepsilon$} & $1110 \mathrm{r}, 90 \mathrm{~V}$ & r & YYr.0, 910 & داخل المجموعات & \multirow{3}{*}{$\begin{array}{l}\text { اكتئاب } \\
\text { PHQ9 }\end{array}$} & \\
\hline لصاح & & $11 \varepsilon, \varepsilon 9$ & $1 \cdot 1$. & אד, ו ו & بين المجموعات & & \\
\hline المنخفضين & & & $1 \cdot 1 r$ & IrV৭\&।, •VA & الكلي & & \\
\hline
\end{tabular}

ونوضح النتائج الموضحة بالجدول (9) المن وجود فروق في الحساسية الانفعالية لدني طلاب

الجامعة بحسب مستويات القلق العام (عالي، متوسط، منخفض)؛ ومستويات الاكتئاب (لا يوجد، بسيط، مكتئب) لصالح حيث وصلت قيمة ف لمستويات دلالة إحصائية مرتفعة ( ( . , · ) مما يشير إلي أن الطلاب ذوي المستوي المرتفع من القلق أكثر حساسية انفعالية من الطلاب ذوي المستوي المنخفض من القلق وهذا يشير إلي أن مستوي القلق لدي الفرد يؤثر في درجة حساسيته الانفعالية ، وأنه كلما ارتفع مستوي القلق لدي الفرد زادمستوي الحساسية الانفعالية لديه، كذلك، أوضحت النتائج أيضا وجود فروق ذات دلالة إحصائية في جودة الحياة لدئ طلاب الجامعة وفق مستويات كل من القلق العام والاكتئاب لصالح حيث وصلت قيمة ف لمستويات دلالة إحصائية مرتفعة (1 · , · ) مما يشير المي أن درجة القلق لدي الفرد تؤثر علي إحساسه بجودة حياته ، وأنه كلما ارتفع مستوي القلق لدي الفرد ، كلما انخفض شعورة بجودة الحياة.

الفرض الخامس: تساهم المتغيرات المستقلة: الحساسية الانفعالية، القلق العام، الاكتئاب في التنبؤ بجودة الحياة لدنئ طلاب الجامعة. وتم اختبار صحة الفرض احصائيا باستخدام تحليل الانحدار الخطي 
بطريقة Enter باعتبار جودة الحياة متغير تابع ومتغيرات القلق العام والحساسية الانفعالية والاكتئاب متغيرات مستقلة. ويوضح الجمول ( • ( ) بيان بنتائج اختبار صحة الفرض احصائيا

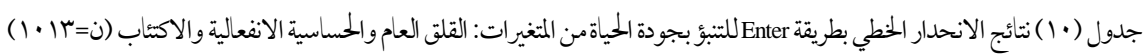

\begin{tabular}{|c|c|c|c|c|c|c|}
\hline \multicolumn{2}{|c|}{$\begin{array}{l}\text { Std. Error of the } \\
\text { Estimate }\end{array}$} & Adjusted R Square & R Square & $\mathbf{R}$ & النموذج & \multirow{2}{*}{ البواقي } \\
\hline \multicolumn{2}{|c|}{10.81701} & .142 & .144 & $.380^{\mathrm{a}}$ & 1 & \\
\hline الدلالة & قيمة ف & متوسط المربعات & درجات الحرية & بجموع المربعات & النموذج & \multirow{4}{*}{ التباين } \\
\hline \multirow{3}{*}{ دالة } & \multirow{3}{*}{56.636} & 6626.802 & 3 & 19880.406 & 1 & \\
\hline & & 117.008 & 1009 & 118060.672 & الانحدار & \\
\hline & & & 1012 & 137941.078 & البواقي & \\
\hline الدلالة & 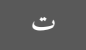 & بيتا & الحطأ ألمعياري & B & النموذج & \\
\hline 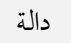 & 22.525 & & 4.529 & 102.011 & الثابت & \\
\hline دالة & -3.988 & -.152 & . 089 & -.356 & العلق & \\
\hline 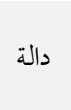 & -2.844 & -.094 & .067 & -.190 & الانفعالية & الأبو \\
\hline دالة & -5.677 & -.211 & .055 & -.311 & لهاملتون & \\
\hline
\end{tabular}

ومن الجمدول (• (1) يمكن اشتقاق معادلة التبنؤ علنى النحو التلاي:

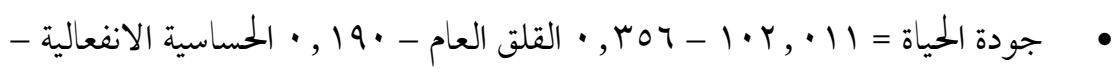

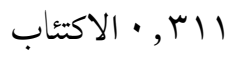

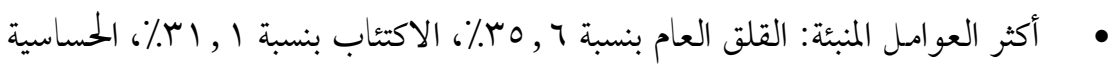

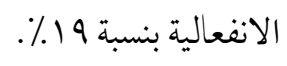




\section{توصيات}

- - اجراء برامج ارشادية لطلاب الجامعة بهدف التخفيف من تأثيرات كل من القلق والاكتئاب

$$
\text { والحساسية الانفعالية حتخى يتم تحسين جودة الحياة لديهم. }
$$

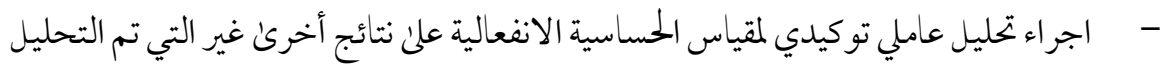
عليها، فمن الواجب اجر اءه علن عينة غختلفة عن عينة التحليل العاملي الاستكشافي. 


\section{المراجع العربية}

أبوهاشم، السيد محمد. ( • • (Y). النموذج البنائي للعلاقات بين السعادة النفسية والعوامل الخمسة الكبرئ للشخصية وتقدير الذات والمساندة الاجتماعية لدئ طلاب الجامعة. بجلة كلية

\section{التربية، جامعة بنها.}

ابو حماد، ناصرالدين ابراهيم. (9 ( + ). جودة الحياة النفسية وعلاقتها بالسعادة النفسية والقيمة

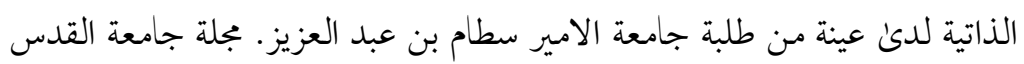

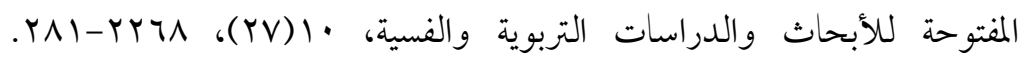
doi:DOI: https://doi.org/10.5281/zenodo.2654292 أبو شمالة، اياد عبد الرحمن محمد. (Y (Y). ادارة الذات كتغير وسيط بين الحساسية الانفعالية والتوجه نحو الحياة للطلبة ذوي الاعاقة السمعية برنامج التعليم الجامعي بالجامعة الاسلامية بغزة. غزة: رسالة ماجستير غير منشورة بكلية التربية - جامعة الاقصئ. ابو منصور، حنان خضر. (11 • ( ). الحساسية الانفعالية وعلاقتها بالمهارات الاجتهاعية لدئ المعاقين سمعيا. غزة: رسالة ماجستير غير منشورة، الجامعة الإسلامية. حزةة، فاطيمة. (1) • Y). تقنين مقياس جودة الحياة المختصر الصادر عن منظمة الصحة العاملية (BREF-WHOQOL)

$$
.10 \mathrm{~V}-1 \mathrm{rag}(\mathrm{r}) \mathrm{V}
$$

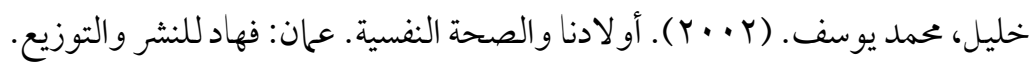
داهم، فوزية. (10 • (Y). جودة الحياة وعلاقتها بالأفكار اللاعقلانية المرتبطة بقلق الامتحان لدئ تلاميذ السنة الثالثة ثانوي. الجزائر: رسالة ماجستير غير منشورة- جامعة الشهيد حمه

$$
\text { لخضر بالو ادي- كلية العلوم الاجتماعية والإنسانية-قسم العلوم الاجتماعية. }
$$

الربابعة، مهدي محمد سعيد. (YV) (Y). علاقة جودة الحياة بالقبول الاجتماعي واستراتيجيات

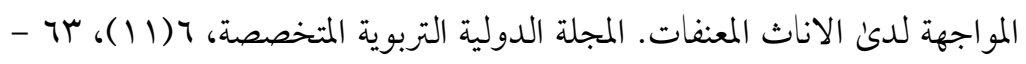

$$
. \wedge \cdot
$$


سلامة، ممدوحة. ( (994 ) . قر اءات مختارة في علم النفس. القاهرة: مكتبة الانجلو المصرية.

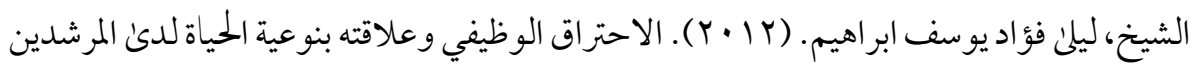
النفسيين والتربويين في المؤسسات الحكومية والخاصة في محافظات" جنين، نابلس، طولكرم. فلسطين: رسالة ماجستير غير منشورة جامعة القدس.

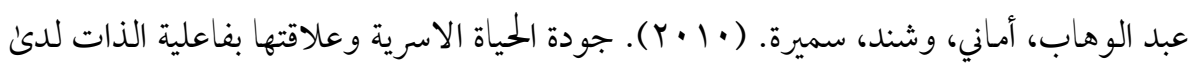
عينة من الابناء المراهقين. المؤتمر السنوي الخامس عشر. القاهرة: مركز الارشاد النفسي جامعة عين شمس. عبد حمزة، عماد. (7 ( ץ). الحساسية الانفعالية لدئ طلبة الجامعة وفاعلية الإرشاد بفرض المفهوم الخاطئ (ريمي)في التقليل من فرط الحساسية السبية. جامعة المثنى، ا-1 ب. تم https://www.researchgate.net/publication/321587924 الاسترداد من 


\section{References:}

AlHadi, A., AlAteeq, D., Al-Shari, E., Bawazeer, H., Alanazi, A., AlShomrani, A., . . AlOwaybil, R. (2017). An arabic translation, reliability, and validation of Patient Health Questionnaire in a Saudi sample. Ann Gen Psychiatry, 16(32), 1-9. doi:DOI 10.1186/s12991-017-0155-1

Attwood, A. S. (2017). State anxiety and emotional face recognition in healthy volunteers. Royal Society Open Science, 4(5), 1-16. Retrieved from https://doi.org/10.1098/rsos.160855

Barbieri, V. A. (2020). The uflyence of rejaection sensitivity and peqr of negative evaluation on emotion recognition. American University, Washington, D.C.: Submitted to the Faculty of the College of Arts and Sciences of American University for Master of Arts in Psychology.

Bentler, P. M. Multivariate analysis with latent variables: Causal modeling. In M. R. Rosenzweig \& L. W. Porter (Eds.), Annual review of psychology (Vol. 31). Palo Alto, Calif.: Annual Reviews, 1980.

Bollen, K. A. (1989), Sample Size and Bentler and Bonett's Nonnormed Fit Index," Psychometrika, 51, 375-377.

Browne, M. W., \& Cudeck, R. (1993). Alternative ways of assessing model fit. In: K. A. Bollen \& J. S. Long (Eds.), Testing structural equation models (pp. 136-162). Beverly Hills, CA: Sage.

Bui, E.; Anderson, E.; Goetter, E. M.; Campbell, A.; Barrett, E. (2017). . Heightened sensitivity to emotional ex-pressions in generalized anxiety disorder, compared to social anxiety disorder, and controls. Cognition \& Emotion, 31(1), 119-126. Retrieved from https://doi.org/10.1080/02699931.2015.1087973

Carmines, E.G., \& Mclver, J. P. (1981). Analyzing models with unobserved Variables. In G. W. Bohrnstedt \& E. F. Borgatta (Eds.), Social measurement: Current Issues, Beverly Hills, CA: Sage.

Carrozzino, D., Patierno, C., Fava, G., \& Guidi, J. (2020). The Hamilton Rating Scales for Depression: A Critical Review of Clinimetric Properties of Different 
Versions. Psychother Psychosom(89), 133-150. doi:DOI: $10.1159 / 000506879$

Coyne, J. C. (1976). Depression and the response of others. Journal of Abnormal psychology, 85(2), 186. doi:. http://dx.doi.org/10.1037/0021843X.85.2.186

Diener, E. (2000). Subjective well-being: the science of happiness and a proposal for a national index. Am Psychol., 55(1), 34.

Diener, E., Wirtz, D., Tov, W., Kim-Prieto, C., Choi, D.-w., Oishi, S., \& BiswasDiener, R. (2010). New Well-being Measures: Short Scales to Assess Flourishing and Positive and Negative Feelings. Soc Indic Res(97), 143156. doi:DOI 10.1007/s11205-009-9493-y

Downey, G., \& Feldman, S. I. (1996). Implications of rejection sensitivity for intimate relationships. Journal of Personality and Social Psychology, 70(6), 13271343.

Downey, G., \& Feldman, S. I. (1996). Implications of rejection sensitivity for intimate relationships. Journal of Personality and Social Psychology, 70(6), 13271343. doi:http://dx.doi.org/10.1037/0022-3514.70.6.1327.

Fischer, A., Kret, M., \& Broekens, J. (2018). Gender differences in emotion perception and self-. PLoS ONE, 13(1), 1-19. doi:e0190712. https://doi.org/10.1371/journal.

Gao, J., \& McLellan, R. (2018). Using Ryff's scales of psychological well-being in adolescents in mainland China. BMC Psychology, 6(17), 1-8. doi:https://doi.org/10.1186/s40359-018-0231-6

Gin-Gin Gan, F., \& Yuen-Ling Hue, M. (2019). Anxiety, depression and quality of life of medical students. Med J Malaysia, 74(1), 57-71.

Gregory, T., \& Brinkman, S. (2015). Development of the Australian Student Wellbeing survey: Measuring the key aspects of social and emotional wellbeing during middle childhood. the Fraser Mustard Centre. Department for Education and Child Development and the Telethon Kids Institute Adelaide. 
Guarino, L. R. (2003). Emotional Sensitivity: A New Measure of Emotional Lability and its Moderating Role IN the Stress-Illnes Relationship. New York: Thesis submitted for the degree of Doctor of Philosophy,University of York,Department of Psychology.

Hair, J., Black, W., Babin, B., Anderson, R., \& Tatham, R. (2006). Multivariate data analysis (6th Ed.). Upper saddle River, N.J.: Pearson Prentice Hall.

Hamilton, M. (1960). A rating scale for depression. J Neurol Neurosurg Psychiatry(62), 23-56.

Huppert, F. A. (2009). Psychological Well-being: Evidence Regarding its Causes and Consequences. Applied Psychology: Health and Well-Being, 1(2), 137164. doi:doi:10.1111/j.1758-0854.2009.01008.x

Innamorati, M., Balsamo, M., Fairfield, B., Fabbricatore, M., Tamburello, A., \& Saggino, a. A. (2014). Construct Validity and Reliability of the Adult Rejection Sensitivity Questionnaire: A Comparison of Three Factor Models. Depression Research and Treatment, Volume 2014, Article ID 972424,, 1-10. doi:http://dx.doi.org/10.1155/2014/972424

Jovev, M., Chanen, A., Green, M., Cotton, S., Proffitt, T., Coltheart, M., \& Jackson, H. (2011). Emotional sensitivity in youth with borderline personality pathology. Psychiatry Research, 187, 234-240.

Kern, M. e. (2015). The EPOCH Measure of Adolescent Well-Being. Psychological Assessment. Advance online publication. doi:http://dx.doi.org/10.1037/pas0000201.

Kraines, M. A., Kelberer, L. J., \& Wells, T. T. (2018). Rejection sensitivity, interpersonal rejection, and attention for emotional facial expressions. Journal of Behavior Therapy and Experimental Psychiatry, 59, 31-39. doi:https://doi.org/10.1016/j.jbtep.2017.11.004

Kutz, A., Marshall, E., Bernstein, A., \& Zvolensky, M. J. (2010). Evaluating emotional sensitivity and tolerance factors in the prediction of panic-relevant responding to a biological challenge. Journal of Anxiety Disorders, 24, 16-22. doi:doi:10.1016/j.janxdis.2009.07.025 
Lebois, L. A., A.Palermo, C., S.Scheuer, L., P.Lebois, E., R.Winternitz, S., LauraGermine, \& L.Kaufman, M. (2020). Higher integration scores are associated with facial emotion perception differences in dissociative identity disorder. Journal of Psychiatric Research, 123(4), 164-170. doi:https://doi.org/10.1016/j.jpsychires.2020.02.007

Marston, E. G., Hare, A., \& Allen, J. P. (2010). Rejection Sensitivity in Late Adolescence: Social and Emotional Sequelae. JOURNAL OF RESEARCH ON ADOLESCENCE, 20(4), 959-982. doi:DOI: 10.1111/j.1532-7795.2010.00675.x

Perdighe, C., Cosentin, T., P. F., Gragnani, A., Saliani, A., \& Mancini, F. (2015). Individual differences in guilt sensitivity: the guilt sensitivity scale(GSS). TPM, 22(3), 349-362. doi:doi:10.4473/TPM22.3.3

Pontin, E., Schwannauer, M., Tai, S., \& Kinderman, P. (2013). A UK validation of a general measure of subjective well-being: the modified BBC subjective well-being scale (BBC-SWB). Pontin et al. Health and Quality of Life Outcomes, 11(1), 1-9. doi:http://www.hqlo.com/content/11/1/150

Quimet, A. J., Kane, L., \& Tutino, J. S. (2016). fear of anxiety or fear of emotions?Anxiety sensitivity is indirectly related to anxiety and depressive syptomes via emotion regulations. Cogent Psychology, 3(1249132), 1-18. doi:https://doi.org/10.1080/23311908.2016.1249132

Rutter, A. L., Scheuer, L., Vahia, I., Forester, B., Smoller, J., \& Germine, L. (2019). Emotion sensitivity and self-reported syptomes of generalized anxiety disorder across the lifespan: A population-based sample approach. Brain and Behavior, 1-7. doi:DOI: 10.1002/brb3.1282

Ryff, C. (1989). Happiness is everything, or is it? Explorations on the meaning of psychological well-being. J Pers Soc Psychol., 57(6), 1069-81.

Ryff, C., Spring, B., \& Loive, G. (2004). Positive health : Connecting well-being with biology. Biological Sciences(359), 1383-1394. 
Schumacher, R. E. \& Lomax, R. G. (2004) A Biginner's Guide to Structural Equation Modeling (2nd Edition). New J: Lawrence Erlbaum Associates Publishers.

Seligman, M. F. (2011). A Visionary New Understanding of Happiness and Wellbeing. New York: Free Press.

Spitzer RL, K., Williams, J., \& Lowe, B. (1999). Patient Health Questionnaire Primary Care Study Group. Validation and utility of a self-report version of PRIME-MD: the PHQ primary care study. JAMA(282), :1737-1744.

Surcinelli, P.; Codispoti, M.; Montebarocci, O., R (2006). Facial emotion recognition in trait anxiety. Journal of Anxiety Disorders, 110-117. Retrieved from . https://doi.org/10.1016/j.janxdis.2004.11.010

Tanaka, J. S., \& Huba, G. J. (1985). A fit index for covariance structure models under arbitrary GLS estimation. British Journal of Mathematical and Statistical Psychology, 38, 197-201.

Usman, R., \& Khan, M. (2019). Rejection Sensitivity, Depression, Self Esteem, Quality of life and Coping. EC Psychology and Psychiatry, 8(6), 528-537.

WHOQOL, G. (1995). The World Health Organization Quality of Life assessment. social science and medicine, 41(10), 1403-1409.

Williams, J., \& Lowe, B. (2006). A breif measure of assessing generalized anxiety disorder: the GAD-7. ARCH Intern Med, 166(10), 1092-7. doi: 10.1001/archinte.166.10.1092 